\title{
Identification and functional analysis of novel genes expressed in the Anterior Visceral Endoderm
}

\author{
LISA GONÇALVES\#,1,2,3, MÁRIO FILIPE\#,3, SARA MARQUES ${ }^{1,2,3}$, ANA-MARISA SALGUEIRO1,2,3, JORG D. \\ BECKER $^{3}$ and JOSÉ ANTÓNIO BELO*,1,2,3 \\ ${ }^{1}$ Regenerative Medicine Program, Departamento de Ciências Biomédicas e Medicina, Universidade do \\ Algarve, ${ }^{2}$ IBB-Institute for Biotechnology and Bioengineering, Centro de Biomedicina, Molecular e \\ Estrutural, Universidade do Algarve, Campus de Gambelas, Faro and ${ }^{3}$ Instituto Gulbenkian de Ciência, \\ 2781-901 Oeiras, Portugal
}

\begin{abstract}
During early vertebrate development, the correct establishment of the body axes is critical. The anterior pole of the mouse embryo is established when Distal Visceral Endoderm (DVE) cells migrate to form the Anterior Visceral Endoderm (AVE). Symmetrical expression of Lefty1, Cer1 and Dkk1 determines the direction of DVE migration and the future anterior side. In addition to the establishment of the Anterior-Posterior axis, the AVE has also been implicated in anterior neural specification. To better understand the role of the AVE in these processes, we have performed a differential screening using Affymetrix GeneChip technology with AVE cells isolated from cer1P-EGFP transgenic mouse embryos. We found 175 genes which were upregulated in the AVE and 36 genes in the Proximal-posterior sample. Using DAVID software, we characterized the AVE cell population regarding cellular component, molecular function and biological processes. Among the genes that were found to be upregulated in the AVE, several novel genes were identified. Four of these transcripts displaying high-fold change in the AVE were further characterized by in situ hybridization in early stages of development in order to validate the screening. From those four selected genes, one, denominated Adtk1, was chosen to be functionally characterized by targeted inactivation in ES cells. Adtk1 encodes for a serine/threonine kinase. Adtk1 null mutants are smaller and present short limbs due to decreased mineralization, suggesting a potential role in chondrogenesis during limb development. Taken together, these data point to the importance of reporting novel genes present in the AVE.
\end{abstract}

KEY WORDS: AVE, affymetrix chip, cerberus, ES cell, gene targeting

\section{Introduction}

The vertebrate body plan is generated through a series of morphogenetic and inductive processes that occur during embryonic development. Some of the earliest developmental events that play a pivotal role in the specification of the body plan are the establishment of the embryonic axes (reviewed in Lu et al., 2001; Takaoka et al., 2007; Belo et al., 2009).

The isolation of Cerberus and Dickkopf1 (Dkk1), secreted proteins able to induce exclusively anterior head structures when misexpressed on the ventral side of the Xenopus embryo, provided the first molecular evidence for the existence of a specific anterior neural inducing activity (reviewed in Belo et al., 2009).
The Cerberus protein was shown to bind Xnr1, BMP4 and Xwnt8, thereby inhibiting their activity, while Dkk1 inhibits Wnt signaling by binding and antagonizing the LRP5/6 co-receptor (Mao et al., 2001; Piccolo et al., 1999). The inhibition of these three signaling pathways (Xnr1, BMP and Xwnt), is considered to be essential for the specification of anterior neural character in the rostral neuroectoderm (reviewed in Belo et al., 2009).

\footnotetext{
Abbreviations used in this paper: Ad, anterior-distal; AVE, anterior visceral endoderm; DAVID, Database for Annotation, Visualization, and Integrated Discovery; DVE, distal visceral endoderm; GO, gene ontology; Pp, posterior proximal.
}

*Address correspondence to: José António Belo. Universidade do Algarve, Campus de Gambelas, 8005-139 Faro, Portugal. e-mail: jbelo@ualg.pt Supplementary Material (six tables) for this paper is available at: http://dx.doi.org/10.1387/ijdb.103273lg

\# Note: These authors contributed equally to this work.

Accepted: 6 April 2011. Final author corrected PDF published online: 6 May 2011.

ISSN: Online 1696-3547, Print 0214-6282

() 2011 UBC Press

Printed in Spain 
Transplantation experiments with mouse nodes and early gastrula organizers show that the induced axis has a posterior neural character and no ectopic head structures are formed (reviewed in Lu et al., 2001). These findings suggested that the necessary anterior neural inducing signals derive from tissues other than or in addition to the node/organizer.

The visceral endoderm, which surrounds the epiblast and the extraembryonic endoderm, forms at the distal tip of the egg cylinder at embryonic day 5.5. The following unilateral polarized movement of these cells towards the proximal region of the embryo, becoming the Anterior Visceral Endoderm (AVE), establishes the future anterior pole and imparts anterior identity upon the underlying epiblast (reviewed in Takaoka et al., 2007, Lu et al., 2001).

The role played by the AVE in the determination of the anteroposterior (A-P) axis and primary induction of the rostral neuroectoderm, has already been described (Perea-Gomez et al., 2001; Shawlot et al., 1999). Several homologs of known anterior neural inducers in Xenopus were found to be expressed in the AVE, such as Nodal, Wnt and BMP signaling inhibitors cer1, dkk1 and also lefty1 and sfrp5 (Belo et al., 1997; Shawlot et al., 1998). In addition, several transcription factors involved in forebrain specification, like otx2, lim1, hnf-3 $\beta$, gsc, hex and hesx1, were also found to be expressed in the AVE before prechordal plate formation (Belo et al., 1997; Thomas et al., 1998). Furthermore, the signaling molecules Nodal and FGF8, which are necessary for gastrulation, are transiently expressed in the AVE at the same time that their expression in the epiblast becomes progressively restricted to the site of primitive streak formation (reviewed in Takaoka et al., 2007).

Despite the large amount of data the supporting a role of AVE in the establishment of A-P axis and anterior neural induction, the mechanisms underlying those processes have only been superficially approached. There is still a gap in the understanding of the molecular pathways involved in the anterior neural induction by the AVE. Presently, the molecular mechanisms contributing to the specification of the AVE, the cues directing its anteriorward movement and the mechanisms underlying the interplay between the AVE and the proximal epiblast/ extraembryonic ectoderm remain poorly understood. The specific gene population of the AVE hasn't yet been well characterized concerning cellular component, molecular function and biological processes. Furthermore, the specific cellular composition and gene expression accounting for the molecular functions and biological processes of the AVE have yet not been well characterized.

In order to gain further insight into the molecular mechanisms involved in early forebrain induction, we have conducted a large-scale screen to identify genes specifically expressed in the AVE.

From this differential screening several novel genes upregulated in the AVE were identified. From those, four novel genes with high fold change were selected for further analysis. One of these novel genes encodes for a protein with tyrosine kinase and serine/threonine kinase domains that we have denominated Adtk1 for Anterior Distal Tyrosine Kinase.

In order to better understand the role of Adtk1 gene during embryonic development, a targeted inactivation was performed (Imuta et al., 2009, Kinoshita et al., 2009 and this study). We have found that these mutants present shortening of the long bones of the limbs, and that the severity of this phenotype is background dependent.

\section{Results}

\section{Affymetrix GeneChip ${ }^{\circledR}$ expression profiling of Anterior-distal and Posterior-proximal regions}

We have designed a new strategy involving the use of Affymetrix GeneChip $^{\circledR}$ arrays to generate gene expression profiles from Anterior-distal (Ad) and Posterior-proximal (Pp) regions of E5.5 mouse embryos. The transgenic line Cer1P-GFP (Mesnard et al., 2004) was proven to be essential for this purpose, as it allows to easily visualize the position of the AVE, which was used as a staging criteria. Cer1 is expressed early in the visceral endoderm, at the distal tip of the egg cylinder (Fig. 1A) and as the distal visceral endoderm migrates anteriorwards, cer1 is clearly restricted to the endodermal layer (Fig. 1B). Consequently, by using the Cer1P-GFP transgenic line, it was possible to separate the Anterior-distal population of cells, from the Posterior-proximal one (Fig. 1C). Thus, complex biotinylated target RNA (cRNA) samples were prepared from Ad and Pp regions of E5.5 embryos in which the distal visceral endoderm had started to migrate and localized at a lateraldistal position. Subsequently, the biotinylated cRNA were hybridized in GeneChip ${ }^{\circledR}$ arrays and we have identified subsets of genes differentially expressed in Ad and Pp regions through the comparison of the gene expression profiles
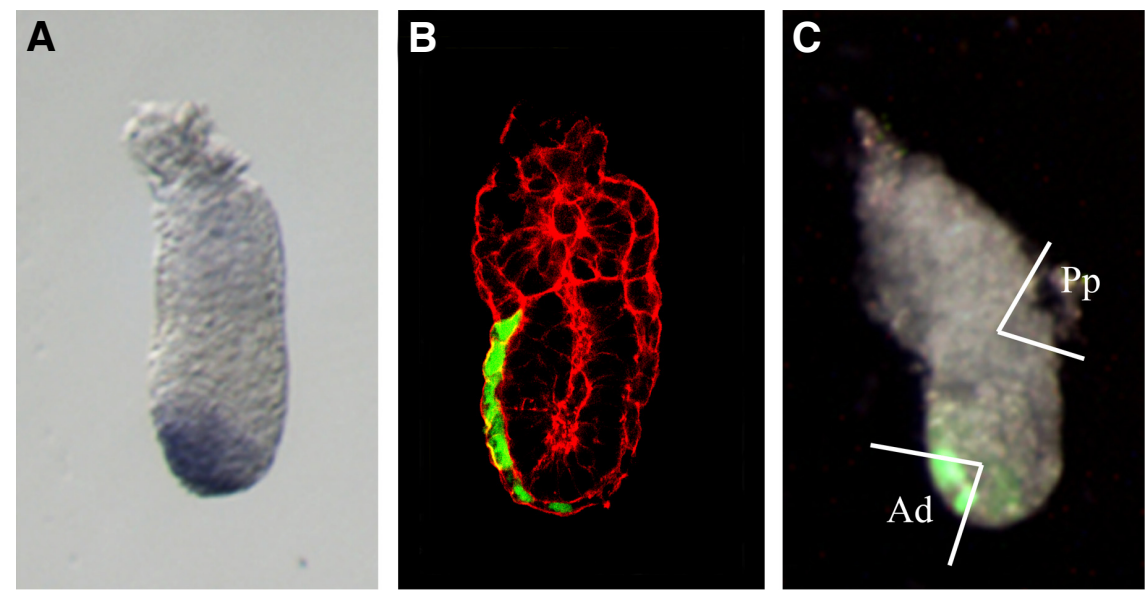

Fig. 1. cer1 expression in the mouse embryo at E5.5. (A) In situ hybridization for cer1 shows that it is expressed at E5.5 in the visceral endoderm, at the distal tip of the egg cylinder. (B) Confocal fluorescence image of a Cer1P-GFP transgenic E5.5 embryo. The green labeled cells show the GFP fluorescence driven by Cer1 promoter as the distal visceral endoderm migrates to establish the anterior pole. Red fluorescence shows F-actin phalloidin labeling. (C) Ad and Pp regions (dashed areas) were isolated from Cer1P-GFP transgenic E5.5 embryos in which the AVE occupied a lateraldistal position: schematization of the regions which were microdissected for the differential screening. The Ad region was isolated from fragments comprising the fluorescently labeled AVE and the underlying epiblast. Pp regions were isolated by dissecting triangular-shaped fragments from a position diametrically opposed to the fluorescently-labeled domain. 


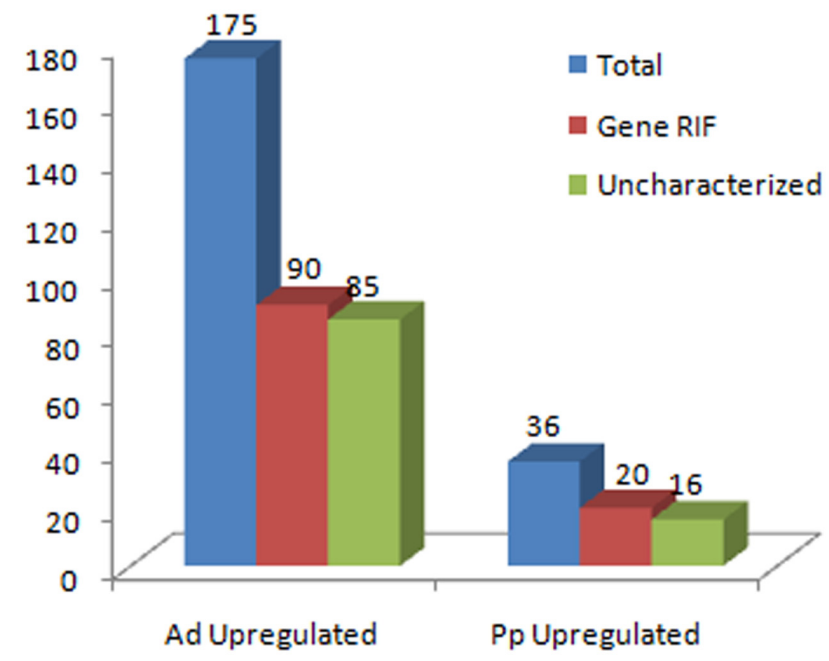

Fig. 2. Number of genes differentially upregulated in the Anterior Visceral Endoderm (AVE) and in the Posterior proximal (Pp) population. In this genetic profiling of an E5.5 mouse embryo, 175 genes were found to be upregulated in the AVE and 36 genes in the Pp population. From this pool of genes 110 present GeneRIF and 101 remain uncharacterized.

from both samples.

For comparison of global gene expression in these two cell populations, the array data was normalized to the median geneexpression levels. After normalization and filtration of the genes to include only those exhibiting over 1.5 fold, 210 genes were identified as being differentially expressed in the Anterior-distal versus Posterior-proximal populations. From these differentially expressed genes, 175 were found to be upregulated in the $\mathrm{Ad}$ population (Table 1), whereas 36 genes were upregulated in the Pp population (Table 2, Fig. 2). These genes were analyzed at a statistical significance of $P<0.1$ (see Supplementary Tables of "DAVID" software data). Interestingly, from this pool of genes, at least 95\% present a PubMed ID: this is due to the fact that the mouse genome was sequenced, and being in the middle of an explosion of genomic information and automatic annotation, practically all genes, hypothetical or already known, were entered into databases.

However, we can only consider a little more than $50 \%$ as characterized (considering characterized genes the ones which present a Gene Reference Into Function), which leaves about 101 uncharacterized genes present in these two populations (Fig. 2).

As expected, reference genes expression such as GAPDH and Actb, showed no difference between the Ad and Pp populations (Fig. 3).

Furthermore, the upregulation of lefty1, cer1, gsc, hesx1, Ihx1 (lim1), foxa2 (hnf3 $\beta)$ and otx2 genes that are expressed in the Ad region and absent from the Proximal-posterior part of the embryo (Meno et al., 1998; Belo et al., 1997; Blum et al., 1992; Shawlot et al., 1998; Thomas et al., 1998), validated the experiment (Fig. 3). On the other hand, nanog and $t b \times 3$ which are genes pre- viously reported to be expressed in the $\mathrm{Pp}$ region were identified as being upregulated in the Pp sample (Fig. 3), and substantiate the correct microdissection of the posterior proximal region of the egg cylinder.

Using DAVID bioinformatics software (Huang et al., 2009; Dennis et al., 2003), a perspective on the cellular component, molecular functions and biological processes of the two gene populations, the Ad-upregulated population and the Ppupregulated population, was obtained by gene ontology (GO) classification of the two sets of features (Fig. 4).

The majority of the genes from both $\mathrm{Ad}$ and Pp populations were correlated to an intracellular location, particularly to the nucleus (Fig. 4A),

When analyzing the predicted molecular function of the genes found in this screening, the molecular function of almost half the genes cannot be predicted (Figure 4B). However, clearly many genes present in the Ad population, encode for protein binding kinases or have themselves potential protein kinase functions, thus possibly playing regulating roles in the different pathways occurring in the AVE. In addition, many genes present in the AVE show potential DNA binding, transcription factor and transcription regulator activities Genes upregulated in the Pp cell population presented no predicted function of protein kinase activity, presenting just a few predicted molecular functions: protein and DNA binding, transcription factor and transcription regulator activity, as well as growth factor activity (Fig. 4B).

Concerning the Biological Processes, as expected, the anterior population is rich in genes involved in embryonic development: gastrulation and anterior/posterior pattern formation (Fig. 4C); from this pool of genes, known genes such as $\lim 1$ and cer1 were detected as being involved in the processes. The Pp population also presents a number of genes which are upregulated and involved in the embryonic development, namely nanog and tbx3 which are involved in promoting pluripotent cell self renewal in embryonic stem cells. Both populations contain genes which

\section{Fold Change (Ad/Pp)}

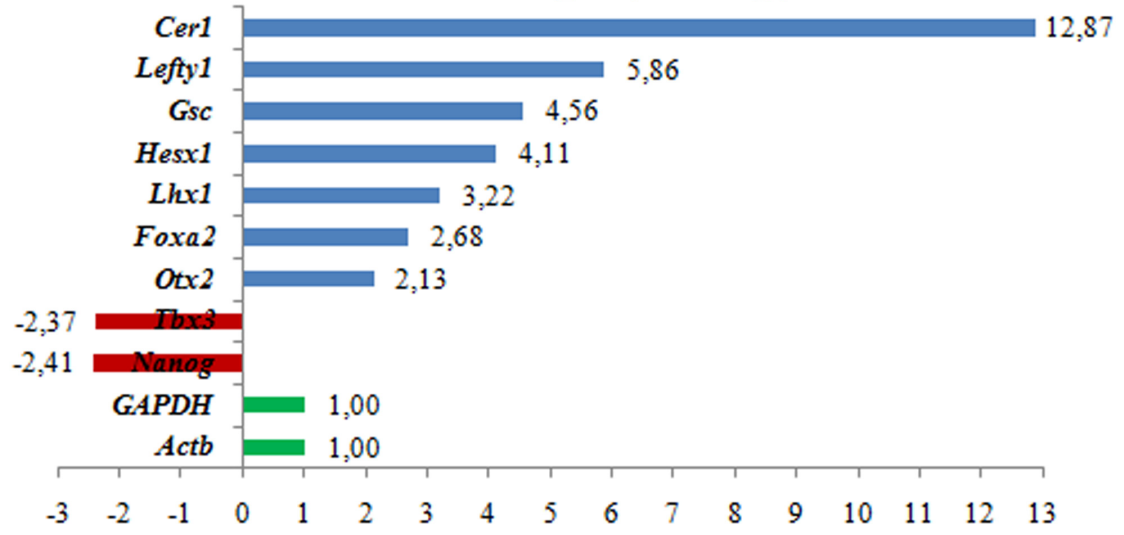

Fig. 3. Graphic view of the fold change of known genes found to be differentially upregulated and downregulated in the AVE, and reference genes. Known AVE markers such as lefty1, cer1, gsc, hesx1, Ihx1, foxa2 and otx2 (in blue) were found to be upregulated in the differential screening. Known markers for the Posterior proximal region such as nanog and tbx3 (in red) were found to be downregulated in the AVE, presenting a negative fold change in the differential screening. Reference genes such as GADPH and Actb (in green) presented no difference in the differential fold change. 


\section{L. Gonçalves et al.}

TABLE 1

\section{LIST OF GENES DIFFERENTIALLY UPREGULATED IN THE ANTERIOR DISTAL REGION}

\begin{tabular}{|c|c|c|c|}
\hline Probe set & Gene & Accession & Fold change \\
\hline 1435464_at & 1110003E01Rik: RIKEN cDNA $1110003 E 01$ gene & BB701294 & 5,12 \\
\hline 1451313_a_at & 1110067D22Rik: RIKEN cDNA 1110067D22 gene & BC019131 & 2,32 \\
\hline 1428628_at & 1190002A17Rik: RIKEN cDNA $1190002 A 17$ gene & AK004439 & 4,98 \\
\hline 1429219_at & 1200009F10Rik: RIKEN cDNA $1200009 F 10$ gene & AK004670 & 2,22 \\
\hline 1439232_at & 1500016L03Rik: RIKEN cDNA 1500016L03 gene & BB781460 & 5,18 \\
\hline 1431567_at & 1700018A04Rik: RIKEN cDNA 1700018A04 gene & AK017122 & 1,67 \\
\hline 1430895_at & 2010109A12Rik: RIKEN cDNA 2010109A12 gene & BF018972 & 4,5 \\
\hline 1456393_at & 2310002J21Rik: RIKEN cDNA 2310002J21 gene & Al642124 & 1,91 \\
\hline 1452227_at & 2310045A20Rik: RIKEN cDNA 2310045A20 gene & BC026655 & 2,09 \\
\hline 1430404_at & 4833416J08Rik: RIKEN cDNA 4833416J08 gene & BM239430 & 2,24 \\
\hline 1434797_at & 6720469N11Rik: RIKEN cDNA 6720469N11 gene & BB054275 & 2,22 \\
\hline 1428535_at & 9430020K01Rik: RIKEN cDNA 9430020K01 gene & AK004276 & 1,85 \\
\hline 1433453_a_at & Abtb2: ankyrin repeat and BTB (POZ) domain containing 2 & BB621938 & 3,08 \\
\hline 1423883_at & Acsl1: acyl-CoA synthetase long-chain family member 1 & BC006692 & 1,74 \\
\hline 1435923_at & Ado: 2-aminoethanethiol (cysteamine) dioxygenase & BB667109 & 1,67 \\
\hline 1418135_at & Aff1: AF4/FMR2 family, member 1 & NM_133919 & 2,13 \\
\hline 1443847_x_at & Aff2: AF4/FMR2 family, member 2 & BB342212 & 2,54 \\
\hline 1435432_at & Agap1: ArfGAP with GTPase domain, ankyrin repeat and PH domain 1 & BE688580 & 1,62 \\
\hline 1435280_at & Al452195: expressed sequence Al452195 & BB303582 & 1,91 \\
\hline 1439341_at & AK220484: cDNA sequence AK220484 & BB203252 & 2,59 \\
\hline 1455454_at & Akr1c19: aldo-keto reductase family 1 , member $\mathrm{C} 19$ & BG073853 & 3,91 \\
\hline 1417704_a_at & Arhgap6: Rho GTPase activating protein 6 & NM_009707 & 1,9 \\
\hline 1441144_at & Arr3: arrestin 3 , retinal & BE984325 & 3,78 \\
\hline 1455083_at & Atp11c: ATPase, class VI, type 11C & BG068357 & 1,89 \\
\hline 1433965_at & Atp8a1: ATPase, aminophospholipid transporter (APLT), class I, type 8A, member 1 & BQ176779 & 2 \\
\hline 1459363_at & Atxn2 /// LOC100047323: ataxin 2 /// similar to ataxin 2 & AV318787 & 2,25 \\
\hline 1444565_at & BB166591: expressed sequence BB166591 & BB136975 & 3,95 \\
\hline 1448733_at & Bmi1: Bmi1 polycomb ring finger oncogene & M64279 & 1,84 \\
\hline 1423635_at & Bmp2: bone morphogenetic protein 2 & AV239587 & 2,95 \\
\hline 1429621_at & Cand2: cullin-associated and neddylation-dissociated 2 (putative) & BM238658 & 1,75 \\
\hline 1439109_at & Ccdc68: coiled-coil domain containing 68 & AV378320 & 4,77 \\
\hline 1416034_at & Cd24a: CD24a antigen & NM_009846 & 2,36 \\
\hline 1418762_at & Cd55: CD55 antigen & NM_010016 & 2,81 \\
\hline 1450256_at & Cer1: cerberus 1 homolog (Xenopus laevis) & AF035579 & 12,87 \\
\hline 1418149_at & Chga: chromogranin A & NM_007693 & 2,41 \\
\hline 1452092_at & Chst15: carbohydrate ( $\mathrm{N}$-acetylgalactosamine 4-sulfate 6-O) sulfotransferase 15 & AK019474 & 2,53 \\
\hline 1434316_at & Chsy1/// LOC100047167: chondroitin sulfate synthase $1 / / /$ similar to mKIAA0990 protein & BQ174991 & 1,58 \\
\hline 1431510_s_at & Cmc1: COX assembly mitochondrial protein homolog (S. cerevisiae) & AK008567 & 1,76 \\
\hline 1423641_s_at & Cnot7: CCR4-NOT transcription complex, subunit 7 & BC006021 & 1,54 \\
\hline 1438920_x_at & Cr1l: Complement component (3b/4b) receptor 1 -like & BF318589 & 1,79 \\
\hline 1441956_s_at & Cux1: Cut-like homeobox 1 & BB025983 & 7,36 \\
\hline 1448710_at & Cxcr4: chemokine (C-X-C motif) receptor 4 & D87747 & 2,14 \\
\hline 1417625_s_at & Cxcr7: chemokine (C-X-C motif) receptor 7 & BC015254 & 2,51 \\
\hline 1442434_at & D8Ertd82e: DNA segment, Chr 8, ERATO Doi 82, expressed & BM195829 & 1,73 \\
\hline 1437929_at & Dact2: dapper homolog 2, antagonist of beta-catenin (xenopus) & AV306847 & 4,34 \\
\hline 1426215_at & Ddc: dopa decarboxylase & AF071068 & 1,94 \\
\hline 1457233_at & Dnaja2: DnaJ (Hsp40) homolog, subfamily A, member 2 & BB324466 & 2,41 \\
\hline 1440278_at & Dynll1: dynein light chain LC8-type 1 & BM939312 & 1,6 \\
\hline 1441891_x_at & Elovl7: ELOVL family member 7, elongation of long chain fatty acids (yeast) & BB338945 & 3,5 \\
\hline 1435436_at & Epas1: endothelial PAS domain protein 1 & Bl647951 & 2,63 \\
\hline 1452163_at & Ets1: E26 avian leukemia oncogene 1, 5' domain & BB151715 & 1,97 \\
\hline 1434202_a_at & Fam107a: family with sequence similarity 107 , member $\mathrm{A}$ & BF682848 & 2,96 \\
\hline 1416892_s_at & Fam107b: family with sequence similarity 107 , member $B$ & BC021353 & 1,8 \\
\hline 1449738_s_at & Fam48a: family with sequence similarity 48 , member $A$ & C80158 & 1,56 \\
\hline 1438883_at & Fgf5: fibroblast growth factor 5 & AV240088 & 1,68 \\
\hline 1451882_a_at & Fgf8: fibroblast growth factor 8 & U18673 & 3,58 \\
\hline 1429310_at & Flrt3: fibronectin leucine rich transmembrane protein 3 & BE945486 & 2,35 \\
\hline 1422833_at & Foxa2: forkhead box A2 & NM_010446 & 2,68 \\
\hline 1437779_at & Foxh1: forkhead box $\mathrm{H} 1$ & BM210256 & 2,01 \\
\hline 1429719_at & Foxp4: forkhead box P4 & AK009204 & 1,57 \\
\hline 1438558_x_at & Foxq1: forkhead box Q1 & AV009267 & 3,6 \\
\hline 1455604_at & Fzd5: frizzled homolog 5 (Drosophila) & BB795235 & 9,51 \\
\hline 1445815_at & Fzd8: frizzled homolog 8 (Drosophila) & BB086994 & 22,94 \\
\hline 1447550_at & Gm8350: predicted gene 8350 & BB545511 & 3 \\
\hline 1443620_at & Gpc4: Glypican 4 & BB212497 & 2,94 \\
\hline 1425458_a_at & Grb10: growth factor receptor bound protein 10 & AF022072 & 1,66 \\
\hline 1421412_at & Gsc: goosecoid homeobox & NM_010351 & 4,56 \\
\hline 1420604_at & Hesx1: homeo box gene expressed in ES cells & NM_010420 & 4,11 \\
\hline 1423319_at & Hhex: hematopoietically expressed homeobox & AK014111 & 2,48 \\
\hline 1456022_at & Hipk2: homeodomain interacting protein kinase 2 & BB554636 & 3,37 \\
\hline 1428433_at & Hipk2: homeodomain interacting protein kinase 2 & AK003718 & 2,27 \\
\hline 1436994_a_at & Hist1h1c: histone cluster 1, $\mathrm{H} 1 \mathrm{c}$ & BB533903 & 2,33 \\
\hline 1452540_a_at & $\begin{array}{l}\text { Hist1h2bc /// Hist1h2be /// Hist1h2bl /// Hist1h2bm /// Hist1h2bp /// LOC100046213 /// LOC665622 /// RP23-38E20.1: } \\
\text { histone cluster 1, H2bc /// histone cluster 1, H2be /// histone cluster 1, H2bl /// histone cluster 1, H2bm /// histone cluster 1, } \\
\text { H2bp /// similar to Hist1h2bj protein /// H2b histone family member /// predicted gene, OTTMUSG00000013203 }\end{array}$ & M25487 & 2,01 \\
\hline 1418072 at & Hist1h2bc: histone cluster 1, H2bc & NM_023422 & 2,1 \\
\hline 1435866_s_at & Hist3h2a: histone cluster $3, \mathrm{H} 2 \mathrm{a}$ & AV297651 & 1,77 \\
\hline 1425900_at & Hkdc1: hexokinase domain containing 1 & BC016235 & 2,8 \\
\hline 1457568_at & Hnrnpd: heterogeneous nuclear ribonucleoprotein D & BB380198 & 1,65 \\
\hline 1429431_at & Ikzf5: IKAROS family zinc finger 5 & AK009564 & 1,87 \\
\hline 1417380_at & Iqgap1: IQ motif containing GTPase activating protein 1 & NM_016721 & 1,68 \\
\hline 1418301_at & Irf6: interferon regulatory factor 6 & NM_016851 & 1,83 \\
\hline 1441429_at & Irs4: insulin receptor substrate 4 & BB295945 & 4,2 \\
\hline 1441317_x_at & Jakmip1: janus kinase and microtubule interacting protein 1 & BB316060 & 2,63 \\
\hline 1441590_at & Kcnj5: potassium inwardly-rectifying channel, subfamily J, member 5 & BB139291 & 6,89 \\
\hline 1435020 at & KIhdc2: kelch domain containing 2 & BE980167 & 1,88 \\
\hline 1424113_at & Lamb1-1: laminin B1 subunit 1 & BG970109 & 2,34 \\
\hline 1423885 at & Lamc1: laminin, gamma 1 & BG066605 & 1,75 \\
\hline
\end{tabular}


TABLE 1 (CONTINUED)

\begin{tabular}{|c|c|}
\hline 1417638_at & Lefty1: left right determination factor 1 \\
\hline 1450428_at & Lhx1: LIM homeobox protein 1 \\
\hline 1454666_at & LOC100046855: similar to BKLF \\
\hline 1428615_at & Lpar6: lysophosphatidic acid receptor 6 \\
\hline 1433858_at & Lrrc28: leucine rich repeat containing 28 \\
\hline 1436767_at & Luc7|2: LUC7-like 2 (S. cerevisiae) \\
\hline 1429274_at & Lypd6b: LY6/PLAUR domain containing 6B \\
\hline 1423294_at & Mest: mesoderm specific transcript \\
\hline 1456439_x_at & Mical1: microtubule associated monoxygenase, calponin and LIM domain containing 1 \\
\hline 1442214_at & de \\
\hline 1441869_x_at & Mm.138375.1 \\
\hline 1447062_at & Mm.138652.1 \\
\hline 1434378_a_at & Mm.148395.2 \\
\hline 1456723_at & Mm.148608.1 \\
\hline 1442067_at & Mm.170274.1 \\
\hline 1420136_a_at & Mm.174122.2 \\
\hline 1458858_at & Mm.182536.1 \\
\hline 1445495_at & Mm.197213.1 \\
\hline 1443166 at & Mm.209168.1 \\
\hline 1458586_at & Mm.209204.1 \\
\hline 1447410_at & Mm.210464.1 \\
\hline 1440935_at & Mm.212560.1 \\
\hline 1460084_at & Mm.214471.1 \\
\hline 1447408_at & Mm.216126.1 \\
\hline 1447314_at & Mm.33043.1 \\
\hline 1459989_at & Mm.7624.1 \\
\hline 1437462_x_at & Mmp15: matrix metallopeptidase 15 \\
\hline 1437250 at & Mreg: melanoregulin \\
\hline 1434087_at & Mthfr: 5,10-methylenetetrahydrofolate reductase \\
\hline 1455238_at & Mum1l1: melanoma associated antigen (mutated) 1-like 1 \\
\hline 1459679_s_at & Myo1b: myosin IB \\
\hline 1448427_at & Ndufa6: NADH dehydrogenase (ubiquinone) 1 alpha subcomplex, 6 (B14) \\
\hline 1437132_x_at & Nedd9: neural precursor cell expressed, developmentally down-regulated gene 9 \\
\hline 1456467_s_at & Nlk: nemo like kinase \\
\hline 1453139_at & Nudt12: nudix (nucleoside diphosphate linked moiety X)-type motif 12 \\
\hline 1456599_at & Nxt2: nuclear transport factor 2 -like export factor 2 \\
\hline 1424086_at & Oaf: OAF homolog (Drosophila) \\
\hline 1425926_a_at & Otx2: orthodenticle homolog 2 (Drosophila) \\
\hline 1433768_at & Palld: palladin, cytoskeletal associated protein \\
\hline 1418304_at & Pcdh21: protocadherin 21 \\
\hline 1421113_at & Pga5: pepsinogen 5 , group I \\
\hline 1427327_at & Pilra: paired immunoglobin-like type 2 receptor alpha \\
\hline 1422041_at & Pilrb1: paired immunoglobin-like type 2 receptor beta 1 \\
\hline 1424797_a_at & Pitx2: paired-like homeodomain transcription factor 2 \\
\hline 1454838_s_at & Pkdcc: protein kinase domain containing, cytoplasmic \\
\hline 1455037_at & Plxna2: plexin A2 \\
\hline 1447864_s_at & Pogk: pogo transposable element with KRAB domain \\
\hline 1424220_a_at & Porcn: porcupine homolog (Drosophila) \\
\hline 1428808_at & Prickle2: prickle-like 2 (Drosophila) \\
\hline 1437539_at & Prkaa1: protein kinase, AMP-activated, alpha 1 catalytic subunit \\
\hline 1420388_at & Prss12: protease, serine, 12 neurotrypsin (motopsin) \\
\hline 1437671_x_at & Prss23: protease, serine, 23 \\
\hline 1448754_at & Rbp1: retinol binding protein 1 , cellular \\
\hline 1434940_x_at & Rgs 19: regulator of G-protein signaling 19 \\
\hline 1434628_a_at & Rhpn2: rhophilin, Rho GTPase binding protein 2 \\
\hline 1431805_a_at & Rhpn2: rhophilin, Rho GTPase binding protein 2 \\
\hline 1440001_at & Rian: RNA imprinted and accumulated in nucleus \\
\hline 1422603_at & Rnase4: ribonuclease, RNase A family 4 \\
\hline 1437983_at & Sall1: sal-like 1 (Drosophila) \\
\hline 1453055_at & Sema6d: sema domain, transmembrane domain (TM), and cytoplasmic domain, (semaphorin) 6D \\
\hline 1452141_a_at & Sepp1: selenoprotein P, plasma, 1 \\
\hline 1460187_at & Sfrp1: secreted frizzled-related protein 1 \\
\hline 1457867_at & Sgpp2: sphingosine-1-phosphate phosphotase 2 \\
\hline 1423852_at & Shisa2: shisa homolog 2 (Xenopus laevis) \\
\hline 1422629 s_at & Shroom3: shroom family member 3 \\
\hline 1453391_at & Speer7-ps1: spermatogenesis associated glutamate (E)-rich protein 7, pseudogene 1 \\
\hline 1455011_at & Stard4: StAR-related lipid transfer (START) domain containing 4 \\
\hline 1439802 at & Stk35: serine/threonine kinase 35 \\
\hline 1429427_s_at & Tcf7l2: transcription factor 7-like 2, T-cell specific, HMG-box \\
\hline 1444769_at & Tex9: Testis expressed gene 9 \\
\hline 1451791 at & Tfpi: tissue factor pathway inhibitor \\
\hline 1433795_at & Tgfbr3: transforming growth factor, beta receptor III \\
\hline 1456981_at & Tmc7: transmembrane channel-like gene family 7 \\
\hline 1437008_x_at & Tmem109: transmembrane protein 109 \\
\hline 1417219_s_at & Tmsb10: thymosin, beta 10 \\
\hline 1436600_at & Tox3: TOX high mobility group box family member 3 \\
\hline 1423310_at & Tpbg: trophoblast glycoprotein \\
\hline 1448737_at & Tspan7: tetraspanin 7 \\
\hline 1452985_at & Uaca: uveal autoantigen with coiled-coil domains and ankyrin repeats \\
\hline 1460455_at & Ubr3: ubiquitin protein ligase E3 component n-recognin 3 \\
\hline 1441018_at & Usp24: ubiquitin specific peptidase 24 \\
\hline 1437615_s_at & Vps37c: vacuolar protein sorting $37 \mathrm{C}$ (yeast) \\
\hline 1435051_at & Wdr44: WD repeat domain 44 \\
\hline 1453737_at & Wipf2: WAS/WASL interacting protein family, member 2 \\
\hline 1443924_at & Wnk3: WNK lysine deficient protein kinase 3 \\
\hline 1437533_at & Xiap: X-linked inhibitor of apoptosis \\
\hline 1447943_x_at & Yeats2: YEATS domain containing 2 \\
\hline 1454901_at & Ypel2: yippee-like 2 (Drosophila) \\
\hline 1455413_at & Zfp11: zinc finger protein 11 \\
\hline
\end{tabular}

\begin{tabular}{|c|c|}
\hline NM_010094 & 5,86 \\
\hline AV335209 & 3,22 \\
\hline AV230488 & 1,84 \\
\hline AK008952 & 1,85 \\
\hline BB667092 & 1,64 \\
\hline BB475271 & 1,77 \\
\hline AK009282 & 1,97 \\
\hline AW555393 & 1,69 \\
\hline BB209438 & 2 \\
\hline BG173293 & 1,96 \\
\hline BB025762 & 2,16 \\
\hline BG073566 & 2,1 \\
\hline BG868949 & 2,15 \\
\hline AV027552 & 2,38 \\
\hline BB468437 & 3,36 \\
\hline Al427540 & 2,33 \\
\hline AW537457 & 1,67 \\
\hline BG078657 & 27,52 \\
\hline BB440867 & 3,25 \\
\hline BB447484 & 2,46 \\
\hline BB712583 & 2,4 \\
\hline BQ176837 & 4,28 \\
\hline BB473929 & 8,76 \\
\hline BM201377 & 2,38 \\
\hline Al480643 & 1,74 \\
\hline AV271189 & 9,76 \\
\hline BB484002 & 2,22 \\
\hline AV298358 & 1,82 \\
\hline BG069750 & 1,72 \\
\hline BB103233 & 2,08 \\
\hline AA406997 & 2,08 \\
\hline NM_025987 & 1,79 \\
\hline BB535494 & 2,24 \\
\hline BB389081 & 1,68 \\
\hline AK018117 & 1,68 \\
\hline BB745947 & 1,91 \\
\hline BC025514 & 2,21 \\
\hline BC017609 & 2,13 \\
\hline BG071905 & 2,28 \\
\hline NM_130878 & 1,91 \\
\hline NM_021453 & 2,13 \\
\hline BB775785 & 2,53 \\
\hline NM_133209 & 2,53 \\
\hline U80011 & 2,03 \\
\hline BB323985 & 5,68 \\
\hline BB002869 & 2,53 \\
\hline AV377712 & 2,08 \\
\hline AB036749 & 2,53 \\
\hline BQ177191 & 2,08 \\
\hline BM236715 & 1,73 \\
\hline NM_008939 & 2,02 \\
\hline ВВ378796 & 3,04 \\
\hline NM_011254 & 2,58 \\
\hline ВB233670 & 2,17 \\
\hline BF228009 & 1,66 \\
\hline AK004849 & 1,55 \\
\hline BM116147 & 2,03 \\
\hline BC005569 & 1,86 \\
\hline BB739342 & 2,26 \\
\hline BB462688 & 8,4 \\
\hline BC001991 & 1,75 \\
\hline Bl658627 & 2,58 \\
\hline BB360745 & 2,57 \\
\hline BC024118 & 5,11 \\
\hline NM_015756 & 1,74 \\
\hline AK016255 & 7,13 \\
\hline BG089858 & 1,62 \\
\hline AV375248 & 1,92 \\
\hline BB175494 & 2,18 \\
\hline BB428851 & 1,63 \\
\hline AF004833 & 1,96 \\
\hline BM122301 & 3,15 \\
\hline BB428982 & 1,73 \\
\hline BB4777208 & 1,94 \\
\hline NM_025284 & 2,01 \\
\hline BM119957 & 2,82 \\
\hline BQ177165 & 1,62 \\
\hline AF052492 & 2,09 \\
\hline BF466442 & 2,25 \\
\hline BB667784 & 1,57 \\
\hline BB453432 & 6,3 \\
\hline BB270615 & 2,02 \\
\hline AV375936 & 2,33 \\
\hline Bl157060 & 2,03 \\
\hline BB084132 & 1,99 \\
\hline BF134200 & 1,62 \\
\hline BE691095 & 1,88 \\
\hline BG069663 & 2,16 \\
\hline BB053703 & 1,64 \\
\hline
\end{tabular}

Selected genes with fold change equal or higher than 1.5 in the Anterior distal region of an E5.5 embryo. 
A

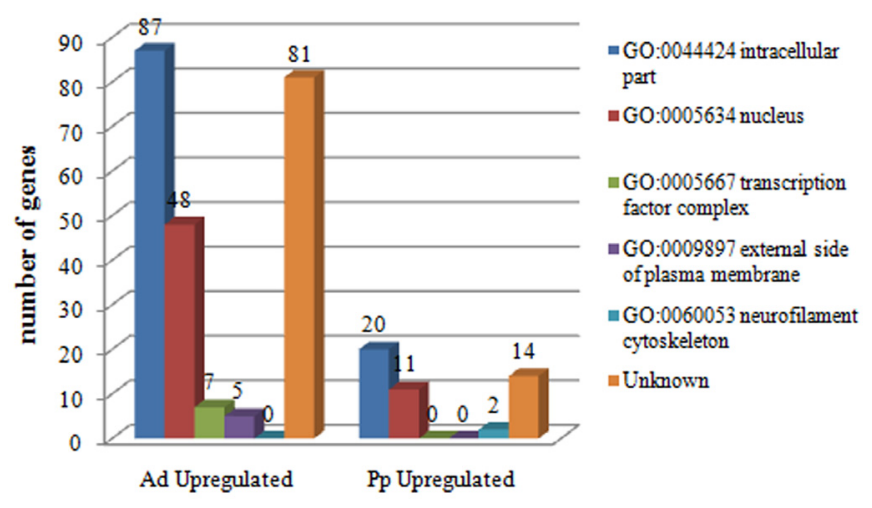

B

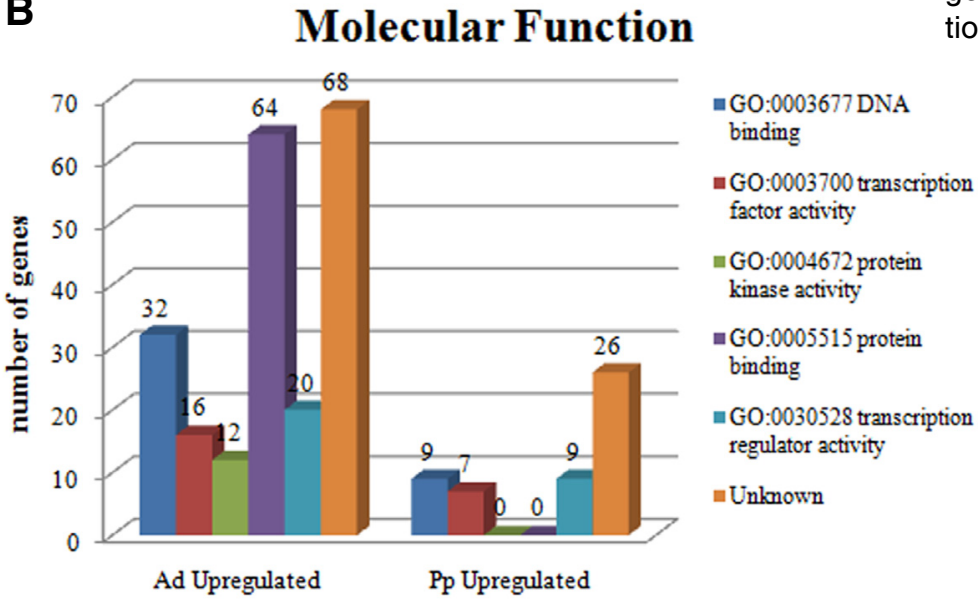

C

Biological Processes

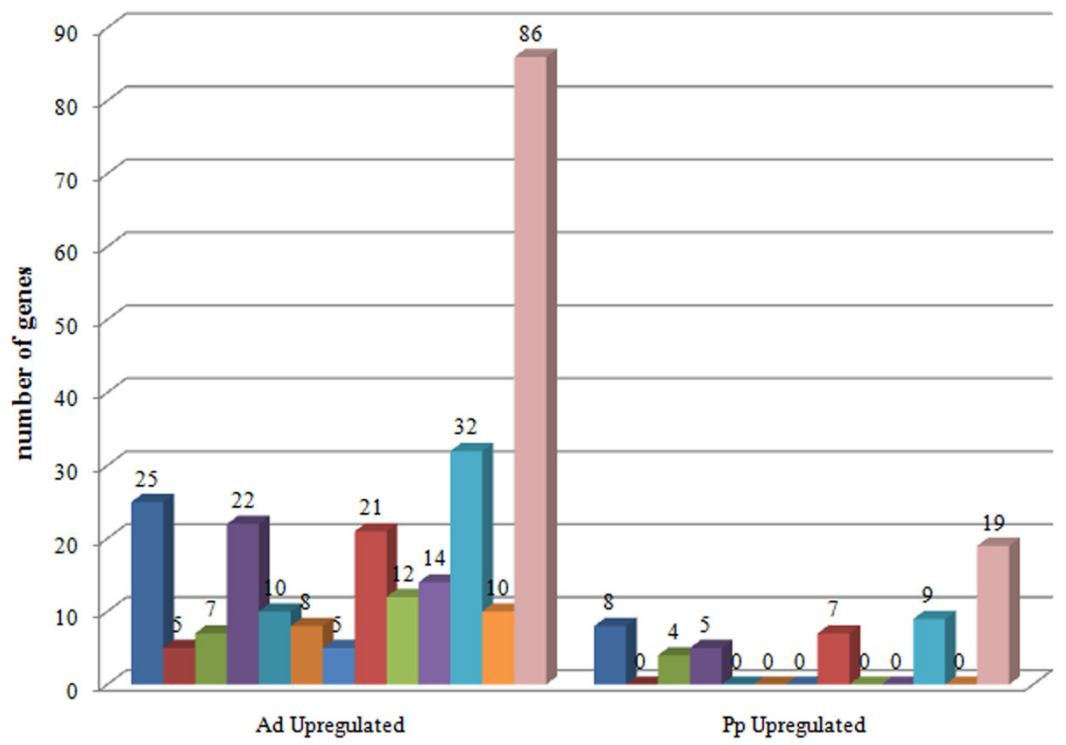

are involved in transcription processes, this corroborates the fact that in the predicted molecular functions transcription factor and transcription regulator activity were detected in the $\mathrm{Ad}$ and $\mathrm{Pp}$ upregulated populations (Fig. 4C). Concerning the Ad upregulated population, there are some genes which are correlated with cell proliferation, being this consistent with the fact that the embryo is in very early stages of development, and the cell proliferating activity at this stage is very high. In the Ad upregulated population genes such as cer1, bmp2 and lim1 were found to be involved in cell proliferation, whereas again $t b x 3$ was detected as gene from the $\mathrm{Pp}$ upregulated population implicated in regulation of cell proliferation (Fig. 4C). Interestingly, both populations present genes which are correlated to heart development, for instance bmp2, foxh1 and pitx2, all involved in heart development, were found to be upregulated in the Ad sample, whereas heart related genes $i d 2$ and $t b x 3$ were present in the Pp upregulated population. Moreover, the Ad upregulated population is also strongly correlated to head and neural tube development, in contrast to the Pp upregulated (Fig. 4C).

Nevertheless, much is still unknown regarding these differentially expressed genetic populations, as many genes, although already sequenced and identified in bioinformatics databases, remain to be studied. Such is the case for $48.6 \%$ for the genes upregulated in the Ad, and for $44,4 \%$ of the Pp upregulated population.

\section{Selection of novel genes upregulated in the AVE}

After data acquisition and normalization, subsets of genes differentially expressed in Ad and $\mathrm{Pp}$ regions were identified by comparison of gene expression levels in both samples. Finally, whole-mount in situ hybridization was used to validate the results from the GeneChip ${ }^{\odot}$ arrays. We selected four genes from the pool of novel, uncharacterized genes found in this AVE differential n GO:0006350 transcription

- GO:0007369 gastrulation

n GO:0007507 heart development

- GO:0009790 embryonic development

- GO:0009952 anterior/posterior pattern formation n GO:0016055 Wnt receptor signaling pathway n GO:0021915 neural tube development - GO:0030154 cell differentiation = GO:0030902, GO:0030900 head development n GO:0042127 regulation of cell proliferation

in GO:0045449 regulation of transcription a GO:0048468 cell development

= Unknown
Fig. 4. Gene ontology (GO) classification of differentially expressed genes in the AVE. Genes that were differentially expressed in the AVE and in the Posterior proximal region (over 1.5 fold and at $\mathrm{P} \leq 0.1$ ) were classified regarding the cellular sub-compartments (A), molecular function (B) and biological processes (C), in order to elucidate the possible functions and processes the novel genes are involved in. Numbers above bars represent the number of genes in each category. screening, with an anteriorposterior differential expression higher than 2-fold change. These genes were provisory named MAd (Mouse Anterodistally) expressed genes.

All the Ad pool selected genes were shown to be expressed very early in mouse embryonic development. Transcripts could be detected as early as embryonic day (E) 5.5 (Fig. $5 \mathrm{~A}, \mathrm{E}, \mathrm{I}, \mathrm{M}$ ) in the AVE, which validated the screening since these genes were identified based on their differential expression in the anterior visceral endoderm.

The novel gene MAd1 (Mouse Anterodistally expressed gene 1, probe set ID 1454838_s_at, Accession number BB323985) was found to have a 5.68 fold change and 
encodes for a 493 aminoacid protein with potential kinase, tyrosine kinase and serine/threonine kinase domains in its amino terminal region. Also, it has a proline-rich region between aminoacids 75 and 128, and an arginine-rich region between aminoacids 49 and 106 (Imuta et al., 2009; Kinoshita et al., 2009). MAd1 was renamed Adtk1 which stands for Anterior Distal Tyrosine Kinase 1.

A characterization of Adtk1 expression pattern by wholemount in situ hybridization (WISH) showed that this gene could be detected in the anterior visceral endoderm (Fig. 5 A,B,Q). Later in development, in early allantoic bud embryos, around E7.25E7.5, Adtk1 transcripts were present in the anterior definitive endoderm (ADE) and in the prospective headfolds (Fig. 5C), and headfolds themselves (Fig. 5D). At early to mid streak stages, Adtk1 transcripts were transiently but very strongly detected, in the primitive streak (Fig. $5 \mathrm{~B})$, and then migrated proximally, towards the extraembryonic region as the streak extended (data not shown). Except for this transient expression in the primitive streak, Adtk1 was always restricted to the most anterior part of the embryo, being absent from the posterior side, throughout mouse embryonic development (data not shown).

MAd2 (Mouse Anterodistally expressed gene 2, probe set ID 1423852_at, Accession number $\mathrm{BC}$ 24118) presented a fold change of 5.11. MAd2 encodes for 295 aminoacid protein which presents two cysteine-rich domains (CRD); interestingly, these CRD have been shown to be highly conserved interspecies (Filipe et al., 2006). A BLAST search (Altschul et al., 1990) of MAd2 sequence as query, returned a Xenopus homolog, which was reported recently by Yamamoto et al., (2005) as Xshisa.

The expression pattern of mouse shisa (Mad2) was analyzed be WISH. shisa transcripts could be detected as early as E5.5 and

Fig. 5. Expression pattern of selected genes during early mouse development (E5.5 to E7.5). Analysis performed by whole-mount in situ hybridization. In situ hybridization of: Adtk1 (A-D), shisa (EH), MAd4 (I-L) and GalNAc4S-6ST (M-P). All genes were found to be expressed in the AVE at E5.5 $(\mathbf{A}, \mathbf{E}, \mathbf{I}, \mathbf{M})$. At E6.5, transcripts of all four selected genes are still present in the AVE $(\mathbf{B}, \mathbf{F}, \mathbf{J}, \mathbf{N})$ and, by E7.0 transcripts are detected in the $A D E(\mathbf{C}, \mathbf{G}, \mathbf{K}, \mathbf{O})$. By early headfold stage, Adtk1, shisa and MAd4 are pesent in the headfolds, whereas GalNAc4S-6ST is detected in the endoderm underlying the prospective headfolds (D,H,I,P). Histological analysis of pregastrulation pos-in situ hybridization embryos show that Adtk1 (0), shisa (R), MAd4 (S) and GalNAc4S6ST (T) are present in the AVE.ADE: Anterior Definitive Endoderm (orange arrowhead); AVE: Anterior Visceral Endoderm (yellow arrowhead); HF: headfolds (green arrowhead); NP: node pit (black arrowhead); PS: primitive streak (blue arrowhead). through embryonic development (Fig. 5 E,F,G,H). At pre- to early streak stages, shisa was shown to be specifically expressed in the AVE (Fig. 5 E,F,R). By late streak stage, expression was found in the anterior definitive endodermal cells that have replaced the AVE (Fig. 5G). In early headfold stage (Fig. H), shisa transcripts could be detected in the cephalic mesenchyme and presumptive forebrain neuroectoderm (Figure $5 \mathrm{H}$ ). Interestingly, in early stages of mouse embryonic development, shisa was always restricted to the most anterior region of the embryo, being excluded from its posterior part (Fig. $5 \mathrm{E}, \mathrm{F}, \mathrm{G}, \mathrm{H}$ ).

MAd4 (Mouse Anterodistally expressed gene 4, probe set ID 1451313_a_at, Accession number BC019131) had a fold change of 2.32. This unknown gene encodes for a 99 aminoacid protein with no homology to known protein domains, although the results
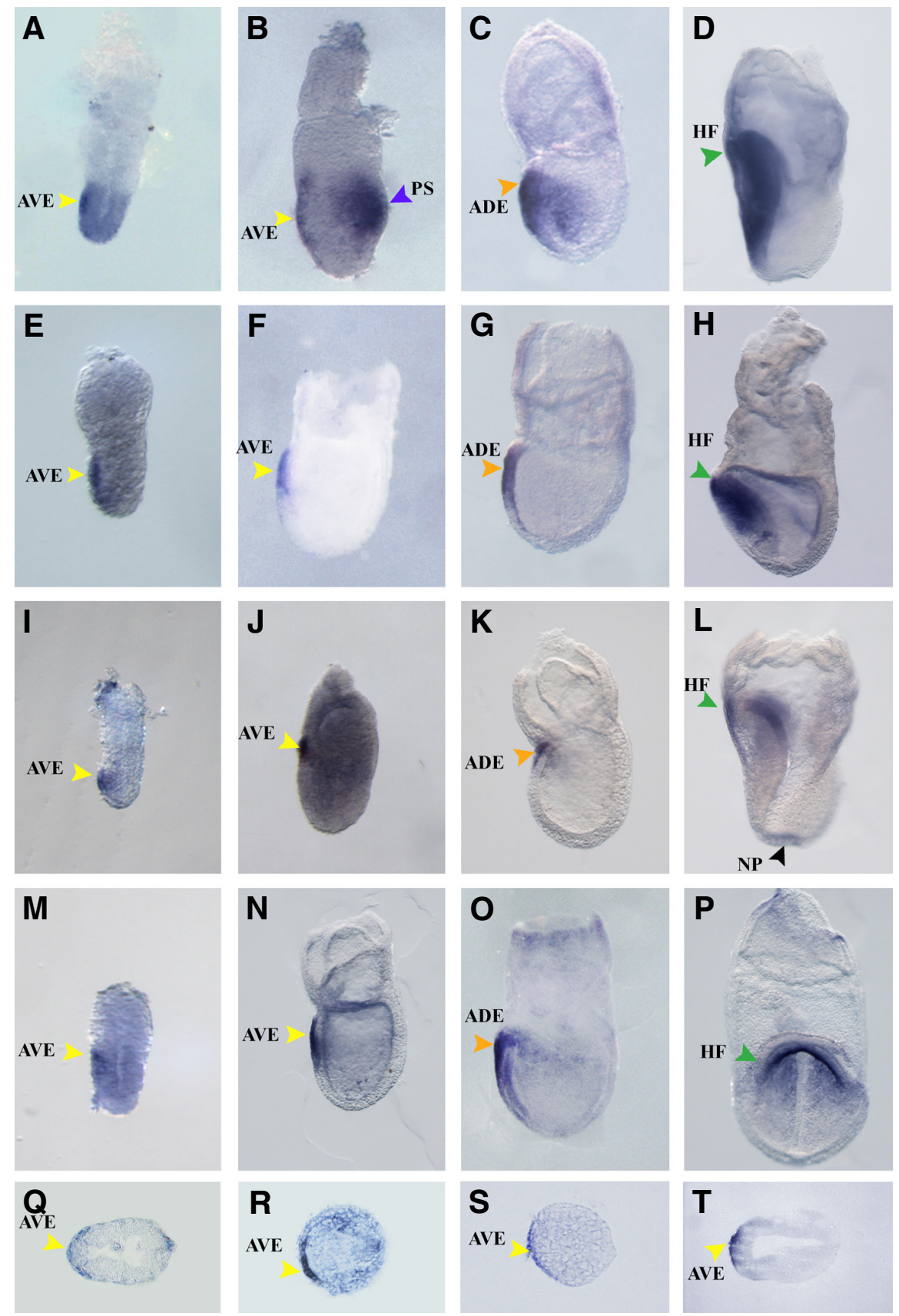
TABLE 2

\section{LIST OF GENES DIFFERENTIALLY UPREGULATED IN THE POSTERIOR PROXIMAL REGION}

\begin{tabular}{|c|c|c|c|}
\hline Probe set & Gene & Accession & Fold change \\
\hline 1439561_at & 2010012O05Rik: RIKEN cDNA 2010012005 gene & BB322051 & $-1,92$ \\
\hline 1432237_at & 5730522E02Rik: RIKEN cDNA 5730522E02 gene & AK017784 & $-3,46$ \\
\hline 1443858_at & 9230105E10Rik: RIKEN cDNA 9230105E10 gene & $\mathrm{B} 1653857$ & $-2,01$ \\
\hline 1434430_s_at & Adora2b /// LOC100045233: adenosine A2b receptor /// similar to Adenosine A2b receptor & BB709140 & $-2,75$ \\
\hline 1430234_at & Arl14: ADP-ribosylation factor-like 14 & AK018621 & $-3,87$ \\
\hline 1428937_at & Atp2b1: ATPase, Ca++ transporting, plasma membrane 1 & $\mathrm{BI} 080417$ & $-1,73$ \\
\hline 1442349_at & C630028N24Rik: RIKEN cDNA C630028N24 gene & Al526947 & $-2,77$ \\
\hline 1424524_at & Dram1: DNA-damage regulated autophagy modulator 1 & BC021433 & $-2,39$ \\
\hline 1456756_at & E430016P22Rik: RIKEN cDNA E430016P22 gene & BB295976 & $-1,58$ \\
\hline 1459133_at & Edem3: ER degradation enhancer, mannosidase alpha-like 3 & BB549831 & $-8,96$ \\
\hline 1448382_at & Ehhadh: enoyl-Coenzyme A, hydratase/3-hydroxyacyl Coenzyme A dehydrogenase & NM_023737 & $-2,3$ \\
\hline 1422823_at & Eps8 /// LOC632638: epidermal growth factor receptor pathway substrate 8 /// similar to Epidermal growth factor receptor kinase substrate 8 & NM_007945 & $-1,6$ \\
\hline 1434458_at & Fst: follistatin & BB444134 & $-3,91$ \\
\hline 1436287_at & Gm10664: predicted gene 10664 & BF466943 & $-2,04$ \\
\hline 1456594_at & Gm1971: predicted gene 1971 & BB728372 & $-1,89$ \\
\hline 1435176_a_at & Id2: inhibitor of DNA binding 2 & BF019883 & $-7,7$ \\
\hline 1433508_at & Klf6: Kruppel-like factor 6 & AV025472 & $-1,66$ \\
\hline 1456060_at & Maf: avian musculoaponeurotic fibrosarcoma (v-maf) AS42 oncogene homolog & AV284857 & $-2,72$ \\
\hline 1421505_at & Mixl1: Mix1 homeobox-like 1 (Xenopus laevis) & AF154573 & $-1,73$ \\
\hline 1439334_at & Mm.121679.1 & BB294794 & $-2,75$ \\
\hline 1445578_at & Mm.157620.1 & BF464298 & $-2,09$ \\
\hline 1459641_at & Mm.172580.1 & C76273 & $-2,16$ \\
\hline 1445333_at & Mm.172659.1 & BG066013 & $-1,84$ \\
\hline 1445020_at & Mm.173888.1 & AU041168 & $-4,49$ \\
\hline 1456753_at & Mm.37466.1 & AW209075 & $-1,92$ \\
\hline 1454672_at & Mm.41752.1 & BE952212 & $-1,7$ \\
\hline 1428818_at & Mon2: MON2 homolog (yeast) & BB663418 & $-2,8$ \\
\hline 1434436_at & Morc4: microrchidia 4 & AV036158 & $-2,24$ \\
\hline 1429388_at & Nanog: Nanog homeobox & AK010332 & $-2,41$ \\
\hline 1422520_at & Nefm: neurofilament, medium polypeptide & NM_008691 & $-1,91$ \\
\hline 1455607_at & Rspo3: R-spondin 3 homolog (Xenopus laevis) & BG072958 & $-3,74$ \\
\hline 1449067_at & SIc2a2: solute carrier family 2 (facilitated glucose transporter), member 2 & NM_031197 & $-3,2$ \\
\hline 1443771_x_at & Smad7: MAD homolog 7 (Drosophila) & BB241324 & $-1,67$ \\
\hline 1440519_at & Sp8: trans-acting transcription factor 8 & AV302930 & $-2,61$ \\
\hline 1437479_x_at & Tbx3: T-box 3 & BB728182 & $-2,37$ \\
\hline 1419537_at & Tcfec: transcription factor EC & NM_031198 & $-3,37$ \\
\hline
\end{tabular}

Selected genes with fold change equal or higher than 1.5 in the Posterior proximal region of an E5.5 embryo

from DAVID analysis point that it might be integral to the membrane.

Early expression pattern of MAd4 was detected by WISH (Fig. $5 \mathrm{I}, \mathrm{J}, \mathrm{K}, \mathrm{L})$. As expected, MAd4 transcripts were present in the AVE, at embryonic day 5.5 (Fig. $5 \mathrm{I}, \mathrm{S}$ ). As the embryo develops and the visceral endoderm is displaced to the most anterior/ proximal region of the egg cylinder, $M A d 4$ was present in the most anterior tip of the visceral endoderm (Fig. 5J), and later, in early allantoic bud embryos, MAd4 expression marked the same region as earlier in the anterior embryonic-extraembrionic boundary of the AVE, that was by then replaced by the anterior definitive endoderm (Fig. 5K). In early headfold stage, MAd4 transcripts could be detected in the most ventral part of the headfolds (Fig. $5 \mathrm{~L})$. Interestingly, in this stage, MAd4 could also be detected in the node pit (Fig. 5L).

MAd5 (Mouse Anterodistally expressed gene 5, probe set ID 1452092_at, Accession number AK019474) obtained a 2.53 fold change. MAd5 encodes for a 561 aminoacid protein: an $N$ Acetylgalactosamine 4-sulfate 6-O-sulfotransferase (GalNAc4S6ST) which is a Golgi-resident enzyme (Salgueiro et al., 2006).
The expression pattern of GaINAc4S-6ST was analyzed by WISH during early mouse embryonic development. As expected, GaINAc4S-6ST could be detected in the AVE by embryonic day 5.5 (Fig.5M). Transcripts could still be detected in this structure by E6.5 (Fig. $5 \mathrm{~N}, \mathrm{~T}$ ). By late-streak stage, GalNAc4S-6ST transcripts become restricted to the anterior definitive endoderm (ADE) which corresponds to the foregut endoderm (Fig. 50). When the embryo reaches early headfold stage, GaINAc4S-6ST could be detected in the endoderm underlying the prospective headfolds (Fig. 5P), which later in embryonic development will give rise to the ventral foregut tube. During early mouse development, GaINAC4S-6ST transcripts were always absent from the posterior region of the egg cylinder.

\section{Analysis of Adtk1 mutants}

From the performed differential screening Adtk1 was detected as being one of the genes with highest fold change in the anterior distal population. This, together with the interesting expression pattern (Fig. $5 \mathrm{~A}-\mathrm{D}$ ), the novelty and the fact that Adtk1 encodes for a serine/threonine tyrosine kinase were critical when choosing 
this gene to proceed with a more detailed study.

When comparing the protein sequences of several different species, one could observe that mouse Adtk1 had high homology with its human homolog, sharing $92 \%$ of identity, and with both its Xenopus and chicken orthologs, sharing 60 and $42 \%$ of identity with Xenopus AdtkL1 and Xenopus AdtkL2, and 37\% identity with chicken AdtkL1 and 28\% identity with chicken AdtkL2 (Fig. 6).

Furthermore, it has been proposed recently that there were indeed two isoforms of mAdtk1. The canonical isoform encodes for a 493 aa protein organized in seven exons (Fig. 7A) whereas, in the second isoform, canonical exon1 was split into non-coding exon1a and partly coding exon1b, (Fig. 7B; Imuta, et al., 2009). In the non-canonical isoform, exon1a consisted of an untranslated (UTR) region. Thus, this short Adtk1 version consisted of eight

60

mAdtk : MRRRRAAVAAGFCASFLLGSVLNVLFAPGS----EPPRPGQSPGSSAAPGPGRRGGRGELARQIRERYEE : 66 hAdtk : MRRRRAAVAAGFCASFLLGSVLNVLFAPGS----EPPRPGQSPEPSPA PGPGRRGGRGELARCIRARYEE : 66 XAdtkL1 : MRRRKIAVAAAFCISFFITTLINI XAdtkL2: --MKNTIILCGAAVSVL--SVFSLLF---------PRP---PSRKSFV---RSERQAELHREILESRRD : 50 CAdtkL1 : cAdtkL2 :

80

100

120

40

mAdtk : VQRYS--RGGPGPGAGR---PERRRLMDLAPGGPGLQRPRPPRVRSPPDGAPGWPPAPGPGSPGPG---- : 127 hAdtk : VQRYS--RGGPGPGAGR---PERRRLMDIAPGGPGLPRPRP PWARPLSDGAPGWPPAPGPGSPGPG---- : 127 XAdtkL1: VLRYRDHRATPPPTSARILRPLERRLMDLAQPQPKWESNKVKR----------GSVSPALGNNKI : 117 XAdtkL2: LLFF------------------LSSLLEG--------------SGADELL-IPGDIMGRTG---- : 78

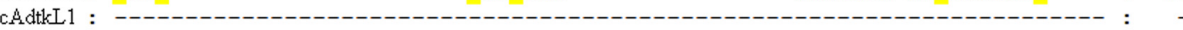
cAdtrT2:
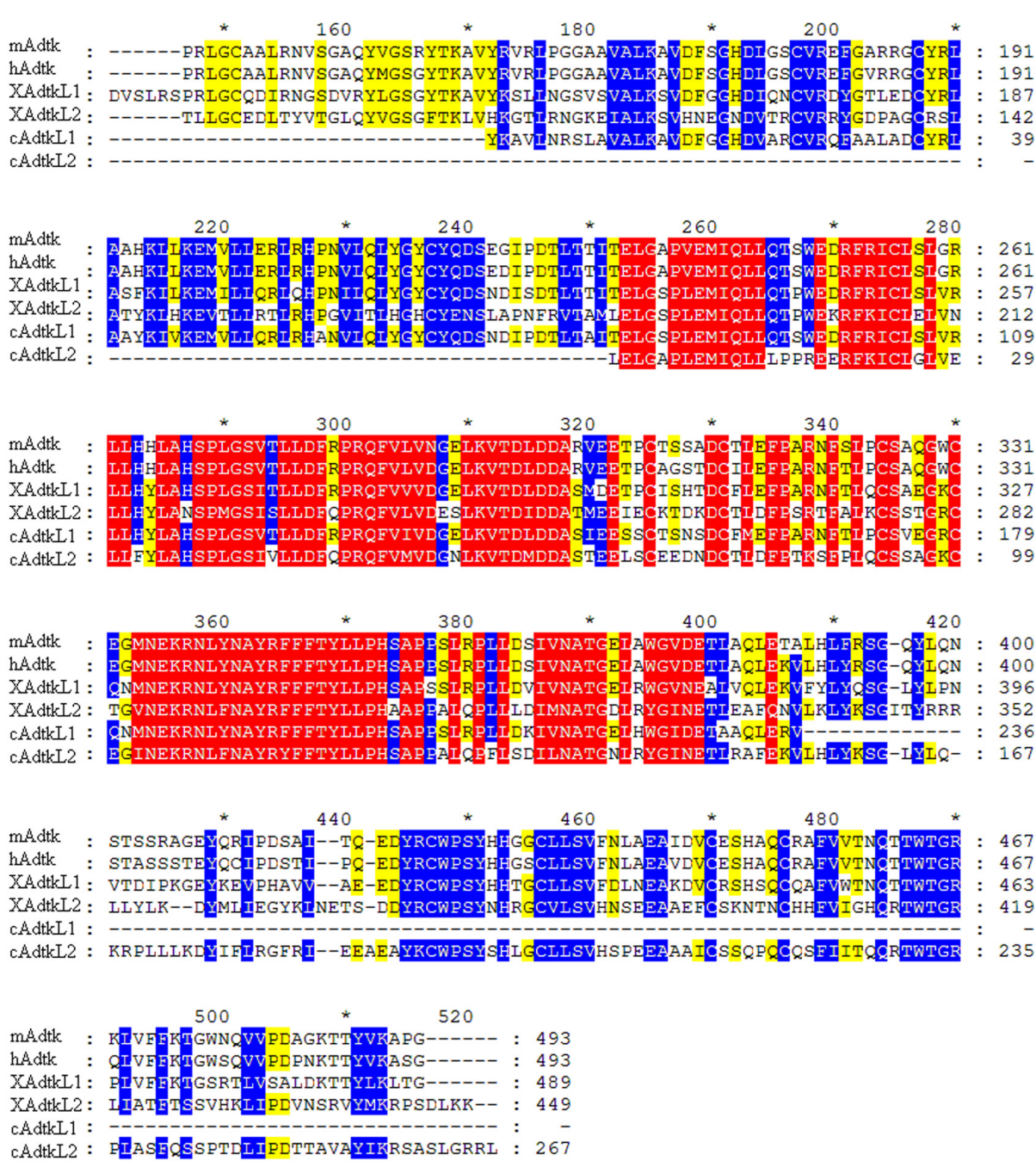

Fig. 6. Predicted protein sequence alignments of mAdtk1, hAdtk1, XAdtk1-L1, XAdtk1-L2, cAdtk1-L1 and cAdtk1-L2. Homologies between the protein sequences are marked by shaded amino acids, With red shades representing the highest homology, and yellow shading the least. $m$, mouse; $h$, human; $X$, Xenopus; $c$, chick. exons, one of them entirely untranslated, and encodes for a 293 aa protein (Fig. 7B). This shorter non-canonical isoform lacked the first 200 aa, and with it, subdomains I, II and III of the serine/threonine tyrosine kinase domain (Hanks and Hunter 1995). Therefore, most likely the shorter isoform will not encode for a fully functional protein kinase. Nevertheless, we wanted to assess whether these two isoforms were being co-expressed during embryonic development. In order to evaluate that, RTPCR was performed in several stages of development. Fig. 7C shows that both isoforms were present throughout E7 to E12 days of embryonic development. A possible explanation is that the long isoform is the fully functional one, and the shorter isoform may be providing a regulatory support.

A targeted inactivation was performed, in order to better understand Adtk1 biological role during mouse embryonic development. For the targeted inactivation we considered the genomic organization of the canonical isoform. In the Adtk1 targeted allele, exon 1 which includes the transcriptional and translational start sites, a part of the upstream region, and intron 1 , were replaced by a PGK neo cassette (Fig. 8A). After ES cell electroporation, and subsequent positive and negative selection with G418 and GANG drugs, respectively, two hundred and forty clones were selected and analyzed, in order to verify if recombination occurred properly. Correct homologous recombination was confirmed by PCR (data not shown) and southern blot (Fig. 8B). The positive clone was injected into mouse blastocysts to generate chimeric mice. The clone produced chimeras, which transmitted the mutant allele to their offspring (Fig. 8C).

The newborn pups obtained from heterozygous intercrosses, were all alive up to $48 \mathrm{~h}$, time when they were collected and sacrificed for posterior analysis. The pups were genotyped, and null mutants were thoroughly analyzed, using littermate wildtype pups as control.

Adtk1 expression pattern suggested a role in head formation, like it has been 
A

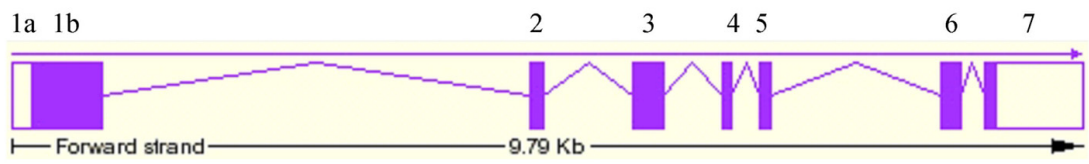

B

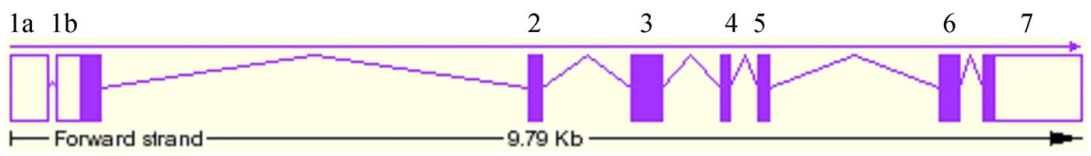

C

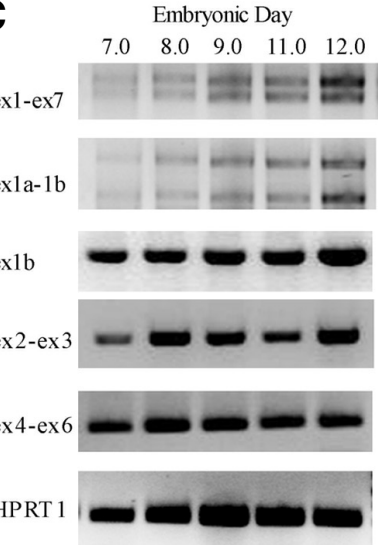

Fig. 7 (Above). Graphic representation of Adtk1. (A) Schematic view of the long version of Adtk1 and its genomic organization. (B) Schematic view of Adtk short version and its genomic organization. (C) Reverse Transcriptase-PCR analyses of Adtk isoforms from days E 7.0 to E12 of mouse development. Total RNA was isolated from mouse embryos at E7.0 (lane 1), E8.0 (lane 2), E9.0 (lane 3), E11.0 (lane 4), and E12.0 (lane 5), and mRNA samples were analyzed with several combinations of primers that anneal in the different exons, and that amplify different regions: ex1-ex7: exon1 to exon7 (top panel); ex1a-ex1b: entire exon1 (second panel); ex1b-partb of exon1(third panel); ex2-ex3: exon2 to exon3 (fourth panel); ex-4ex6: exon4 to exon6 (fifth panel). HPRT (bottom panel) was used as a reference gene, and served as an endogenous control to normalize the differences in the amount of CDNA in each sample).

A

0

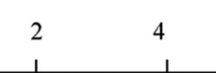

6

8

10

12

14

16

18

20

Wild type allele

$1 \mathrm{~kb}$

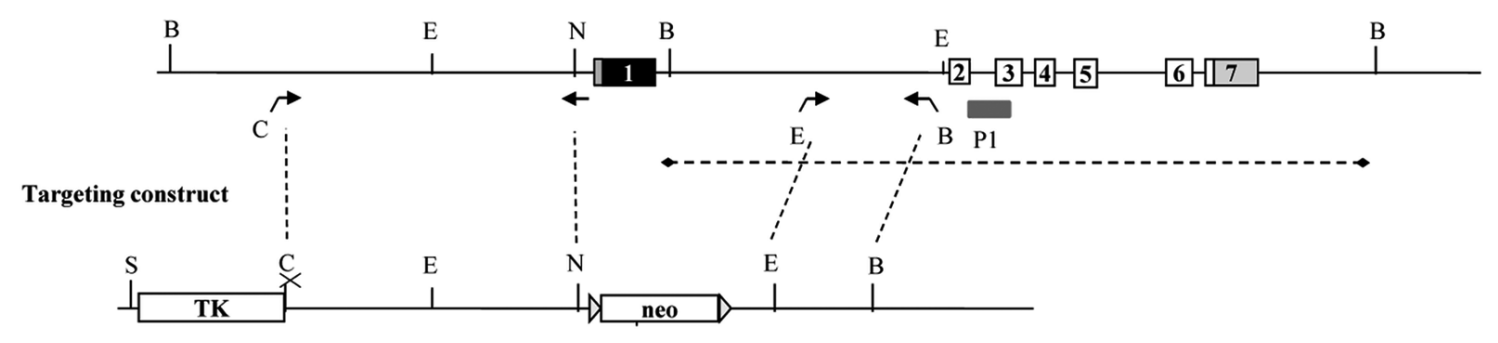

Targeted allele

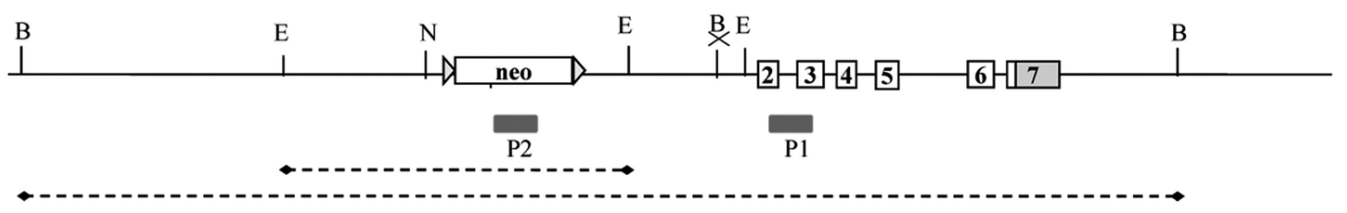

B

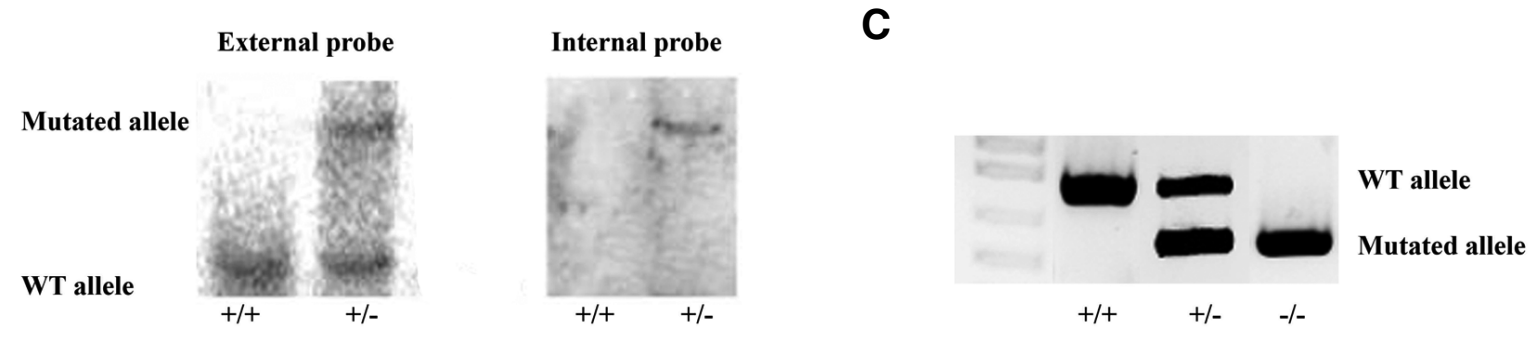



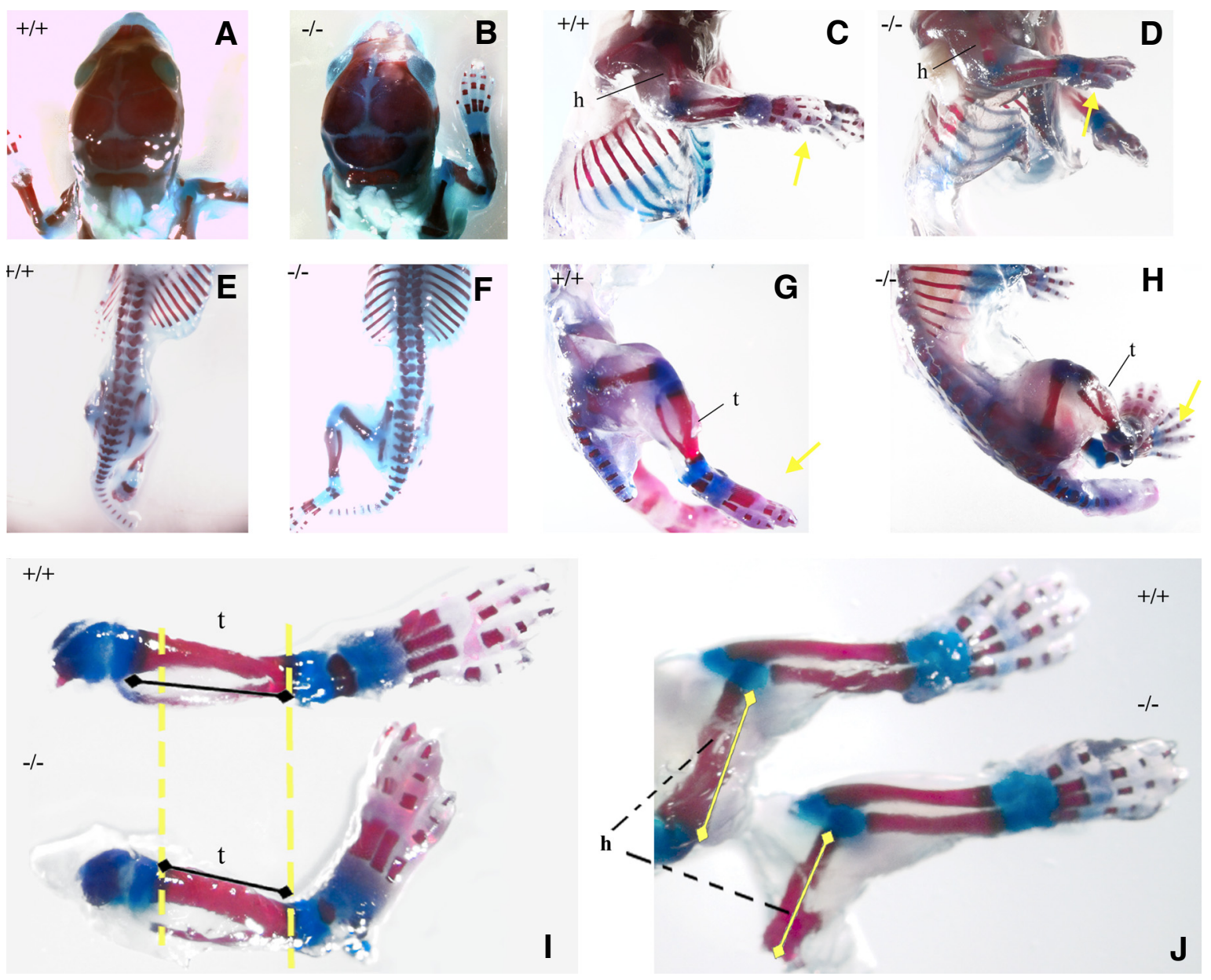

Fig. 9. Skeletal analysis of Adtk1 null mutants and wild type littermates. All skeletons are from the same litter. (C,D,G,H) The right side of the pup. (A,B,E,F) Dorsal view. Skeletons from wild type newborn pup \#32 (A,C,E, G, +/+) and Adtk1 null mutant newborn pup \#35 (B,D, F, H, -/-). I- WT $(+/+)$ and KO (-/-) lower limbs; J-WT (+/+) and KO (-/-) upper limbs. Mineralized regions (bones) are stained red with alizarin red, and cartilage is stained blue with alcian blue. Yellow arrows indicate the paws. Dashed line compares tibia and peroneum lengths, in WT and KO newborns. $t$, tibia; $h$, humerus.

shown for other genes expressed in the AVE such as otx2, $\lim 1$, gsc and cer1 (Shawlot, et al., 1999, Perea-Gomez, et al., 2001, Belo, et al., 1998, Belo, et al., 1997).

Adtk1 null mutants were analyzed through gastrulation to neurulation stages (from E6.5 to E9.5) and no phenotypic differences were obtained comparing with the wild-type littermates (data not shown). This data supports previous experiments reported by Imuta et al., 2009, where in neurulation and organogenesis stages null mutants were similar to wild-type embryos.
The majority of homozygous newborns presented no apparent external defects; and in particular no defects were detected in the anterior structures (Fig. 9 A,B). The internal organs were then evaluated, and no significant differences were observed regarding the external morphology.

All null mutants obtained were slightly smaller than their wildtype littermates, upholding data previously reported by Imuta et al., 2009.

Skeletal analysis with alizarin red and alcian blue was per-

Fig. 8 (Left). Schematic representation of targeted deletion of the Adtk1 gene. (A) Restriction map of Adtk1 genomic region, the targeting construct, and the recombinant allele. The targeted exon is depicted as a filled box, the remaining exons are depicted as white boxes. UTR regions are depicted in gray. The targeting construct contained a Neomycin resistance gene cassette, used for positive selection of recombinant clones, and was flanked by 5' and 3' homology regions. In addition, an HSV-TK cassette was inserted at the end of the 5' arm to allow for negative selection. After BamHI digestion, a probe external to the 3' recombinant arm and a probe in the neo cassette were used in Southern blot analysis (the targeted allele gave rise to a $17 \mathrm{~kb}$ band (panel B, lane 2), and the wild type allele gave a 10.5kb labeled band (panel $B$, lane 1), ). The probe that hybridizes in the neo cassette is also used in Southern blot analysis after EcoRV digestion (this originates a 3.6 kb). PCR primers used to amplify the 5' and 3' homology regions are shown as black arrows. B, BamHI; C, Cla I; E, EcoR V; N, Not I; Sal, Sal I; P1, external 3' southern probe; P2, neo cassette internal probe. (B) Southern blot analysis of a targeted ES cell line. Correct targeting of Adtk1 was confirmed by the presence of a $17 \mathrm{~kb}$ fragment in the BamHI digest of genomic DNA using 3' external probe and an internal probe for neo cassette as a control. (C) Offspring genotype from Adtk1 intercrosses. Wildtype animals present a single band at 864 bps. Heterozygous mutants present the wild-type band at 864 bps and the mutant band at 544 bps Homozygous mutants present a single band at 544 bps. 
formed and provided further and more detailed information. In the limbs, the mineralized regions stained in, were significantly shortened compared with its wild type littermates (Fig. 9 C-J and Table 3 ), whereas the size and morphology of the cartilage, which stained blue, were not significantly affected.

Analysis of $A d t k 1$ null mutants showed that these mutants have indeed shorter hind and forelimbs. In the lower limbs, although the femur is not much affected, the tibia and peroneum sizes are about 30\% shortened (Fig. 9l and Table 3). Regarding the upper limbs, both radio and humerus sizes are 20 to $25 \%$ shortened (Fig. $9 \mathrm{~J}$ and Table 3). As for the cervical vertebrae, no significant changes were observed, and no neural tube defects were detected (Fig. E,F). During embryonic development, as limbs become evident around E9.5, Adtk1 transcripts could always be detected in these structures; curiously during later stages, Adtk1 expression in the limbs is restricted to the most proximal part of the limb (data not shown). This set of data corroborates the data recently published both by Imuta et al., 2009 and Kinoshita et al., 2009 describing Adtk1 null mutants ( $P k d c c$ and VIk) although the phenotypes are a little milder probably due to background differences. Consequently, the analysis of these null mutants was not scrutinized further.

\section{Discussion}

The importance of the AVE during mouse embryonic development has been well demonstrated; either by its removal, which leads to the loss of forebrain structures and anterior markers such as Hesx1 (reviewed in Takaoka et al., 2007), or by the analysis of mutants such as Cripto, Otx2, $\beta$-catenin, or BMPr1 (Perea-Gomez et al., 2001, Liguori et al., 2008, Acampora et al., 2009; Huelsken et al., "2000; Miura et al., 2010), where the DVE fails to migrate towards the anterior side of the egg cylinder resulting in the absence of a correct anterior-posterior axis formation. We have decided to unravel the AVE gene pool in E5.5 embryos because this particular stage represents the beginning of the rotation of the proximal-distal axis $(p-d)$, which will ultimately be converted into the definitive A-P axis at the beginning of gastrulation (reviewed in Lu et al., 2001; Takaoka et al., 2007). The position of the prospective anterior and posterior sides can only be recognized after the AVE initiates its anteriorward movement. Moreover, at this stage the AVE already expresses the majority of its markers, meaning that it is already specified and should be exerting its anteriorizing activity over the underlying epiblast. It is also possible that at such an early stage the molecular cues that direct the AVE towards the anterior side are still present. Therefore this stage presents itself as the more versatile for the analysis of the various mechanisms responsible for the AVE properties

Data from this screening can be analyzed in several ways, depending on the goal. For instance, when analyzing the genes that are upregulated in the AVE and correlated to gastrulation processes, one can obtain large amount of information. As for molecular function, the genes identified as upregulated in the AVE and involved in the process of gastrulation, were all linked to protein binding activity.

Interestingly, most of the genes that are upregulated in the AVE and involved in heart development, are also involved in transcription regulation and correlated with protein binding
TABLE 3

MEASURES OF WT AND ADTK1 NULL MUTANT BONES

\begin{tabular}{lccc} 
& ADTK & WT & ADTK/WT (\%) \\
\hline Humerus & 0,273 & 0,362 & 75,603 \\
Radio & 0,316 & 0,396 & 79,748 \\
Upper paws & 0,262 & 0,334 & 78,497 \\
Femur & 0,324 & 0,331 & 98,012 \\
Tibia & 0,294 & 0,428 & 68,7 \\
Lower paws & 0,546 & 0,604 & 90,333 \\
\hline
\end{tabular}

Bone size in the upper limbs (humerus, radio and paws) and lower limbs (femur, tibia and paws) in $\mathrm{cm}$. Ratio between Adtk and WT bone length.

activity. As for the genes upregulated in the Pp population and involved in heart development, all were also considered to be involved in the biological process of transcription regulation, localized in the nucleus, and all presented transcription regulator activity.

From the pool of genes upregulated in the AVE, only approximately $7 \%$ of the known genes are correlated to head development. As the AVE is a region crucial to the formation of anterior structures (Thomas and Beddington, 1996, Perea-Gomez et al., 2001) one would expect a higher incidence of genes involved in the specification of this kind of structures. Among the known genes upregulated in the AVE and classified as being important for anterior structure specification were otx2 and $\lim 1$. Furthermore, all genes correlated to brain development were also correlated to central nervous system development and the large majority was localized to the intracellular fraction, the nucleus in most cases. Interestingly, none of the genes selected in the $\mathrm{Pp}$ population were correlated with the development of anterior structures or nervous system.

Although the main purpose of this screening was to discover novel genes expressed in the AVE early in development, we were also able to provide new data concerning already known genes and correlate their functions, both at the molecular and biological levels.

From the novel genes selected, it is clear that during early embryonic development, their expression pattern is very similar, being all expressed in the AVE, as expected. However, as the embryo develops, these genes present very interesting and distinct expression patterns (Filipe et al., 2006; Salgueiro et al., 2006), suggesting different roles during development.

It is already clear that strong expression in the AVE is not a synonymous of a role in the development of anterior structures. In the case of shisa the expression pattern suggested a potential role in the development of anterior structures, as this gene is strongly present in the forebrain, cephalic mesenchyme and neuroepithelium of the prosencephalic vesicle (Filipe et al., 2006), and Xenopus Shisa protein promotes head formation (Yamamoto et al., 2005). However, a targeted inactivation of this gene in mouse led to viable and fertile animals (Furushima et al., 2007).

From the screening, Adtk1, a gene that encodes for a protein kinase, was the novel gene expressed in the AVE with highest fold change, which strongly pointed to a role in anterior structure development. The importance of phosphorilation during development has been well established. Interestingly, this gene was also found in a screening for genes downstream of 
Ssdp1 (Single-stranded DNA binding protein 1), a co-activator of the transcription factor Lim1, known to be essential for the development of the prechordal plate, one of the head organizer tissues (Imuta et al., 2009). All this reinforced our belief that Adtk1 had a strong head inducing potential. However, Adtk1 targeted inactivation resulted in shorter limbs and no anterior structure defects as we expected. This phenotype is not as severe as the one reported by Imuta et al., 2009 and Kinoshita et al., 2009, which besides shorter limbs, also report cleft palate defects, which were not found in our analysis of Adtk1 mutants. This phenotypical difference could be accounted for, by the fact both Imuta el al. 2009 and Kinoshita et al., 2009 used TT2 ES cells, whereas the targeting here reported was performed in $\mathrm{C} 57 \mathrm{BI} / 6-\mathrm{cBrd}$ mixed background. It is known that differences in genetic background, which are characterized by specific single nucleotide polymorphisms (SNPs), can be associated with regulatory variations, affecting gene expression levels, and giving rise to different phenotypes.

In addition to the strong expression in anterior structures during all embryonic development, Adtk1 transcripts are also strongly detected in the limbs, immediately as they start to develop, and until later in development. Thus, a potential role in limb development was also expected. The shorter limbs phenotype in Adtk1 mutants is not due to chondrocyte proliferation but due to a delay in the differentiation of hypertrophic chondrocytes (Imuta et al., 2009; Kinoshita et al., 2009). As Adtk1 is always restricted to the most proximal region of the limb, and always excluded from the apical ectodermal ridge, it may be playing a role in the already known Shh/Gremlin/FGF loop. Therefore, it is important to further study this gene, identify its partners, and clarify its role during development.

\section{Conclusions}

Gene-expression profiling in the Anterior-distal and Posterior-proximal populations pinpointed distinct molecular functions. Although both populations are involved in embryonic development, the Ad population is responsible for initial cellular differentiation and processes such as gastrulation and axis specification, whereas genes expressed in the $\mathrm{Pp}$ region are responsible for maintaining a niche of embryonic stem cells, also important for embryonic development. Interestingly, from the genes upregulated in the Ad sample almost $40 \%$ of the genes molecular and biological functions are not yet known. This might explain why much is not clear regarding the pathways involved in AVE specification and anterior structures development. From this screening several unknown genes with expression in the AVE were selected. However, a gene being upregulated with high-fold change in the AVE does not guarantee that it is involved in anterior structure development. In the case of Adtk1 null mutants, for instance, the major defects lie in limb formation. As for shisa (another gene expressed in the AVE with high-fold change), it has also been demonstrated that null mutants for this gene have no apparent phenotype (Furushima et al., 2007) possibly due to gene redundancy other than with shisa paralogues. Accordingly, it would be interesting to determine potential redundancy for Adtk1, assessing the potential genes that compensate for the loss of Adtk1.

Further detailed analysis of the novel genes found to be upregulated in the AVE should be performed, as it may unravel unknown links within and between pathways, which can be of great importance in the study of mouse embryonic development.

\section{Materials and Methods}

\section{Embryo collection}

C57BL/6, B6SJLF1, F1 (C57BL6 x CBA), C57BL/6-Cer1P-GFP and C57BL/6-Adtk1 mice were maintained and bred on an artificial 12-hour light/dark cycle. Embryonic development was staged according to gestational age, designated days post coitum (dpc) or embryonic day $(\mathrm{E})$, with noon of the day of vaginal plug detection being considered $0.5 \mathrm{dpc}$ (or E0.5). To account for variations in the rate of embryonic development between mouse strains and between littermates in each litter, the staging was corrected based on observed morphological landmarks.

Transgenic embryos used for the microdissection of Anterior distal (Ad) and Posterior proximal (Pp) regions were derived from natural matings of B6SJLF1 females x Cer1P-GFP males. Null mutant mice for Adtk1 were analyzed at birth. Wild-type embryos used for the analysis of gene expression by in situ hybridization were collected from natural matings of B6SJLF1 $x$ B6SJLF1. Pregnant females were sacrificed by cervical dislocation and the uteri were surgically removed and placed in ice-cold PBS. Embryos were dissected out of the decidua with fine forceps as described (Hogan et al., 1994), and processed according to their purpose.

\section{Microdissection of Anterior-distal (Ad) and Posterior-proximal (Pp) regions}

Embryos with fluorescently labeled AVE were collected from B6SJLF1 $x$ Cer1P-GFP matings at 5.5-5.75 dpc. Ad and Pp regions were isolated from embryos in which the AVE occupied a lateraldistal position. For the isolation of Ad regions, fragments comprising the fluorescently labeled AVE and the underlying epiblast were microdissected. Pp regions were isolated by dissecting triangular-shaped fragments of proximal visceral endoderm and epiblast from a position diametrically opposed to the fluorescentlylabeled domain. The upper limit of the Pp fragments coincided with the embryonic-extraembryonic boundary and extended in depth to roughly one third of the diameter of the egg cylinder, while its lateral limit corresponded to about one third of the height of the embryonic region. The freshly dissected fragments were immediately homogenized with TRIzol ${ }^{\circledR}$ and frozen in liquid nitrogen. The samples were then stored at $-80^{\circ} \mathrm{C}$ until processing.

\section{Cer1P-GFP confocal imaging}

E6.0 Cer1 P-GFP embryos were collected and briefly incubated with Phalloidin solution in order to label F-actin. Embryos were fixed in $4 \%$ paraformaldehyde, laid on their short axis of bilateral symmetry and scanned by confocal microscopy, using Leica SP5 confocal, to reveal GFP and Phalloidin.

\section{RNA Isolation, Target Synthesis and Hybridization to Affymetrix GeneChips}

Total RNA was extracted from pools of Ad and Pp regions using the Mini RNA Isolation Kit (Zymo Research). Concentration and purity was determined by spectrophotometry and integrity was confirmed using an Agilent 2100 Bioanalyzer (Agilent Technologies, Palo Alto, CA). Due to the low amount of biological material available, a modified linear amplification protocol had to be applied to generate the required amount of probe (Baugh et al., 2001; Klebes et al., 2002; Van Gelder et al., 1990). $15 \mu \mathrm{g}$ of biotinylated cRNA was used in a 300- $\mu$ l hybridization mix containing added hybridization controls. $200 \mu \mathrm{l}$ of mixture was hybridized on Affymetrix (Santa Clara, CA, USA) GeneChip Mouse Expression Set 430 arrays for 16 $\mathrm{h}$ at $45^{\circ} \mathrm{C}$. Standard post hybridization wash and double-stain protocols were used on an Affymetrix GeneChip Fluidics Station 400. Arrays were 
scanned on an Affymetrix GeneChip scanner 2500.

\section{Data analysis}

Scanned arrays were analyzed first with Affymetrix MAS 5.0 software to obtain Absent/Present calls and for subsequent analysis with dChip 2010 (http://www.dchip.org, Wong Lab, Harvard). Each set of 5 arrays (430A and 430B type) was analyzed separately from here on. Each set was normalized applying an Invariant Set Normalization Method. Then the normalized probe cell intensities of the 5 arrays were used to obtain model-based gene expression indices based on a PM-only model. Replicate data for the same sample were weighted gene-wise by using inverse squared standard error as weights. All genes compared were considered to be differentially expressed if the $90 \%$ lower confidence bound of the fold change between experiment and baseline was above 1.5. The lower confidence bound criterion means that we can be $90 \%$ confident that the fold change is a value between the lower confidence bound and a variable upper confidence bound. Li and Wong ( $\mathrm{Li}$ and Hung Wong, 2001) have shown that the lower confidence bound is a conservative estimate of the fold change and therefore more reliable as a ranking statistic for changes in gene expression.

Annotations for the $\sim 34000$ genes represented on the GeneChip Mouse Expression Set 430 were obtained from the NetAffx database (www.affymetrix.com) as of November 2009.

\section{Skeletal analysis, whole mount in situ hybridization and histology}

For the skeletal analysis of the neonates, Alcian Blue/Alizarin Red staining was performed as described in Belo et al., 1998.

Whole mount in situ hybridization and anti-sense probe preparation was carried out as described in Belo et al., (1997). For anti-sense RNA probe synthesis the plasmids containing BC022157 clone (Adtk1), BC009097 clone (MAd4) and BC035443 clone (GalNAc4S-6ST) were digested with Sall restriction enzyme and transcribed using T7 RNA polymerase. The plasmid containing BC05764 clone (shisa) was cut with Bglll and transcribed using T7 RNA polymerase.

Sections were performed and analyzed as described in Filipe et al., (2006).

\section{Generation of ADTK1 mutant mice}

A mouse C57BL/6 Bacterial Artificial Chromosome (BAC) genomic clone, RP24-36006, containing Adtk1 gene, was obtained from BACPAC Resources, Children's Hospital Oakland Research Institute. Using the BAC DNA as a template, a 5' region ranging from 4779 to 284 bp upstream of the transcription start site of exon 1, and a 3' region ranging from 2328 to $3916 \mathrm{bp}$ downstream of the end of exon 1 were generated by Polymerase Chain Reaction (PCR). These genomic fragments were fully sequenced and cloned in a PGK neo floxl plasmid, interspaced by a PGKNeo-pA cassette; and a HSV-TK cassette was also inserted in the construct upstream the 5' homologous arm. This construct was then linearized with Sall and used as a targeting vector. Bruce4 ES cells were then electroporated with the linearized targeting vector, followed by positive and negative selection with G418 and GANG drugs, respectively. ES clones were first screened for homologous recombination by PCR. Proper homologous recombination was confirmed for the clones that were screened positive by PCR, by Southern hybridization of the ES cell genomic DNA using a 3' external genomic probe, and the absence of random targeting-vector insertion was also confirmed, with an internal probe for the neomycin-resistance gene. The positive ES cell clone was injected into $\mathrm{C} 57 \mathrm{BI} / 6 \mathrm{cBrd}$ (albino) blastocysts to produce chimeric mice, at Institut fur Labortierkunde, University of Zurich.

Genotyping was carried out by PCR analysis of adult tail DNA using the following oligonucleotides: AdtkwtFw (5' CAC CGA CTA CAC CTA CAA C 3'), ADTKwtRev (5' ACC ACC ACC AGG AAG CAT GA 3') and AdtkneoFw (5' CTC GAC TGT GCC TTC TAG TT 3'). The wild-type allele was identified using AdtkwtFw and AdtkwtRev oligonucleotides, which amplify a $864 \mathrm{bp}$ band. The presence of the targeted allele was identified using AdtkneoFw and AdtkwtRev oligonucleotides, which amplify a 544 bp targeted allele specific product.

\section{Aknowledgements}

We thank J. E. Bragança and J.M. Inácio for critically reading of this manuscript, Moisés Mallo for help with ES cell work. L. Gonçalves, M. Filipe and A. M. Salgueiro were recipients of PhD fellowships from F.C.T. This work was supported by research grants from F.C.T., from IGC/FCG and from IBB/CBME, LA to J.A. Belo.

\section{References}

ACAMPORA D, DI GIOVANNANTONIO LG, DI SALVIO M, MANCUSO, P and SIMEONE A (2009). Selective inactivation of Otx2 mRNA isoforms reveals isoform-specific requirement for visceral endoderm anteriorization and head morphogenesis and highlights cell diversity in the visceral endoderm. Mech Dev 126: 882-897.

AFFYMETRIX (2003). GeneChip Expression Analysis Technical Manual.

ANDREAZZOLI M (2009). Molecular Regulation of Vertebrate Retina Cell Fate. Birth Defects Res 87: 284-295.

BAUGH LR, HILL AA, BROWN EL and HUNTER CP (2001). Quantitative analysis of mRNA amplification by in vitro transcription. Nucleic Acids Res 29: E29.

BELO JA, BOUWMEESTER T, LEYNS L, KERTESZ N, GALLO M, FOLLETTIE M and DE ROBERTIS EM (1997). Cerberus-like is a secreted factor with neutralizing activity expressed in the anterior primitive endoderm of the mouse gastrula. Mech Dev 68: 45-57.

BELO JA, LEYNS L, YAMADA G. and DE ROBERTIS EM (1998). The prechordal midline of the chondrocranium is defective in Goosecoid-1 mouse mutants. Mech Dev 72: 15-25.

BELO JA, SILVA AC, BORGES AC, FILIPE M, BENTO M, GONÇALVES L VITORINO M, SALGUEIRO AM, TEIXEIRA V, TAVARES AT and MARQUES S (2009). Generating asymmetries in the early vertebrate embryo: the role of the Cerberus-like family. Int. J. Dev. Biol. 53: 1399-1407.

BLUM M, GAUNT SJ, CHO KW, STEINBEISSER H, BLUMBERG B, BITTNER D and DE ROBERTIS EM (1992). Gastrulation in the mouse: the role of the homeobox gene goosecoid. Cell 69: 1097-1106.

DENNIS G JR, SHERMAN BT, HOSACK DA, YANG J, GAO W, LANE HC and LEMPICKI RA (2003). DAVID: Database for Annotation, Visualization, and Integrated Discovery. Genome Biol. 4: P3.

FILIPE M, GONÇALVES L, BENTO M, SILVA AC and BELO JA (2006). Comparative expression of mouse and chicken Shisa homologues during early development. Dev. Dyn. 235: 2567-73.

FURUSHIMA K, YAMAMOTO A, NAGANO T, SHIBATA M, MIYACHI H, ABE T, OHSHIMA N, KIYONARI H and AIZAWA S (2007). Mouse homologues of Shisa antagonistic to Wnt and Fgf signalings. Dev Biol 306:480-492.

HANKS SK, and HUNTER T (1995). The eukaryotic protein kinase superfamily: kinase (catalytic) domain structure and classification. FASEB J 9: 576-596.

HOGAN B, BEDDINGTON R, COSTANTINI F and LACY E (1994). Manipulating the mouse embryo: a laboratory manual. Plainview, N.Y.: Cold Spring Harbor Laboratory Press.

HUANG DW, SHERMAN BT and LEMPICKI RA (2009). Systematic and integrative analysis of large gene lists using DAVID Bioinformatics Resources. Nature Protoc 4: 44-57.

HUELSKEN J, VOGEL R, BRINKMANN V, ERDMANN B, BIRCHMEIER C and BIRCHMEIER W (2000). Requirement for beta-catenin in anterior-posterior axis formation in mice. $J$ Cell Biol 148:567-578.

IMUTA Y, NISHIOKA N, KIYONARI H and SASAKI H (2009). Short Limbs, Cleft Palate, and Delayed Formation of Flat Proliferative Chondrocytes in Mice With Targeted Disruption of a Putative Protein Kinase Gene, Pkdcc (AW548124). Dev Dyn 238: 210-222.

KINOSHITA M, ERA T, JAKT, LM and NISHIKAWA S (2009). The novel protein kinase VIk is essential for stromal function of mesenchymal cells. Development 136: 2069-2079.

KLEBES A, BIEHS B, CIFUENTES F and KORNBERG TB (2002). Expression profiling of Drosophila imaginal discs. Genome Biol 3: research0038.1- 
research0038.16.

LIGUORI GL, BORGES AC, D'ANDREA D, LIGUORO A, GONÇALVES L, SALGUEIRO AM, PÉRSICO MG and BELO JA (2008). Cripto independent nodal signalling promotes positioning of the A-P axis in the early mouse embryo. Dev Biol. 315, 280-289.

LU CC, BRENNAN J and ROBERTSON EJ (2001). From fertilization to gastrulation: axis formation in the mouse embryo. Curr Opin Genet Dev 11: 384-392.

MENO C, SHIMONO A, SAIJOH Y, YASHIRO K, MOCHIDA K, OHISHI S, NOJI S, KONDOH H and HAMADA H (1998). lefty-1 Is Required for Left-Right Determination as a Regulator of lefty-2 and nodal. Cell 94: 287-297

MESNARD D, FILIPE M, BELO JA and ZERNICKA-GOETZ M (2004). The anteriorposterior axis emerges respecting the morphology of the mouse embryo that changes and aligns with the uterus before gastrulation. Curr Biol 14: 184-196.

MIURA S, SINGH AP and MISHINA Y (2010). Bmpr1a is required for proper migration of the AVE through regulation of Dkk1 expression in the pre-streak mouse embryo. Dev Biol 341: 246-254

PEREA-GOMEZ A, LAWSON KA, RHINN M, ZAKIN L, BRULET P, MAZAN S and ANG SL (2001). Otx2 is required for visceral endoderm movement and for the restriction of posterior signals in the epiblast of the mouse embryo. Development 128: 753-765.
SALGUEIRO AM, FILIPE M AND BELOJA (2006). N-acetylgalactosamine 4-sulfate 6-O-sulfotransferase expression during early mouse embryonic development. Int J Dev Biol 50: 705-708.

SHAWLOTW, WAKAMIYAM, KWAN KM, KANIA A, JESSELL TM and BEHRINGER RR (1999). Lim1 is required in both primitive streak-derived tissues and viscera endoderm for head formation in the mouse. Development 126: 4925-4932.

SILVA AC, FILIPE M, KUERNER KM, STEINBEISSER H and BELO JA (2003) Endogenous Cerberus activity is required for anterior head specification in Xenopus. Development 130, 4943-4953.

TAKAOKA K, YAMAMOTO M and HAMADA H. (2007). Origin of body axes in the mouse embryo. Curr Opin Genet Dev 17: 344-350

THOMAS PQ, BROWN A and BEDDINGTON RS (1998). Hex: a homeobox gene revealing periimplantation asymmetry in the mouse embryo and an early transient marker of endothelial cell precursors. Development 125: 85-94.

VAN GELDER RN, VON ZASTROW ME, YOOL A, DEMENT WC, BARCHAS JD and EBERWINE JH (1990). Amplified RNA synthesized from limited quantities of heterogeneous cDNA. Proc Natl Acad Sci USA 87: 1663-1667.

YAMAMOTO A, NAGANO T, TAKEHARA S, HIBI M and AIZAWA S (2005). Shisa promotes head formation through the inhibition of receptor protein maturation for the caudalizing factors, Wnt and FGF. Cell 120: 23-35. 


\section{Further Related Reading, published previously in the Int. J. Dev. Biol.}

See our recent Special Issue Animal Cloning \& Cell Reprogramming

edited by Michele Boiani and José B. Cibelli at:

http://www.ijdb.ehu.es/web/contents.php?vol=54\&issue=11-12

Characterization of the functional properties of the neuroectoderm in mouse Cripto -/-embryos showing severe gastrulation defects Giovanna L. Liguori, Diego Echevarria, Sonia Bonilla, Daniela D’Andrea, Annamaria Liguoro, Maria G. Persico, and Salvador Martinez Int. J. Dev. Biol. (2009) 53: 549-557

Otx2 and HNF3beta genetically interact in anterior patterning O Jin, K Harpal, S L Ang and J Rossant

Int. J. Dev. Biol. (2001) 45: 357-365

The role of Otx2 in organizing the anterior patterning in mouse A Simeone and D Acampora

Int. J. Dev. Biol. (2001) 45: 337-345

Role of the anterior visceral endoderm in restricting posterior signals in the mouse embryo A Perea-Gomez, M Rhinn and S L Ang

Int. J. Dev. Biol. (2001) 45: 311-320

Distinct roles for visceral endoderm during embryonic mouse development

M Bielinska, N Narita and D B Wilson

Int. J. Dev. Biol. (1999) 43: 183-205

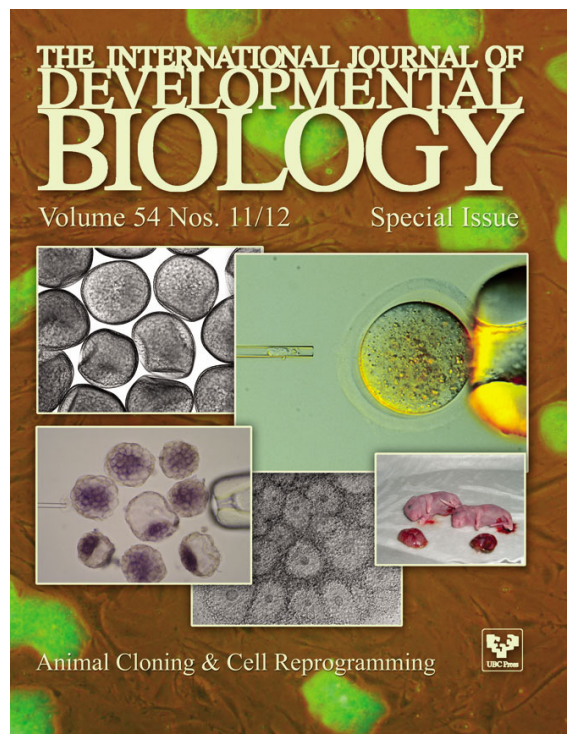

5 yr ISI Impact Factor $(2009)=3.253$

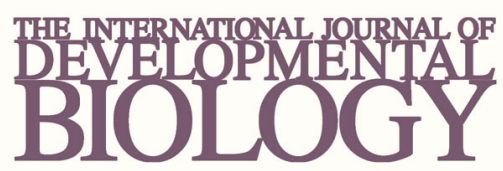

Volume 54 Nos. $6 / 7$
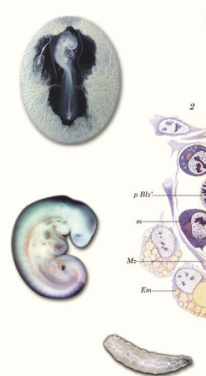

(2) 8
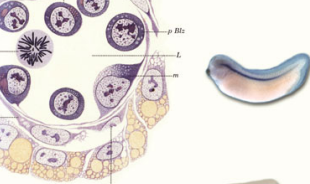

Special Issue

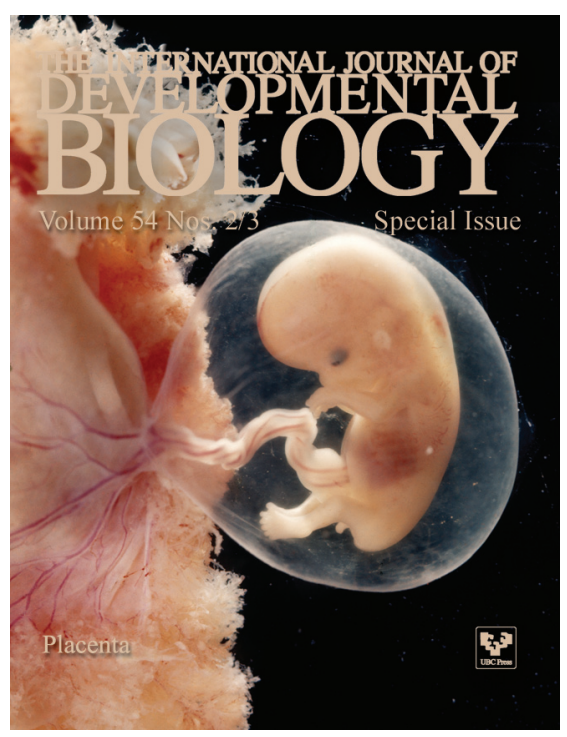

